\title{
ON THE CHANGES IN GLOMERULI AND ARTERIES IN INFLAMMATORY AND ARTERIO-SCLEROTIC KIDNEY DISEASE. ${ }^{1}$
}

\author{
By J. F. Gaskell, M.B., Beit Research Fellow. \\ From the Pathological Institute, Freiburg-i,-Breisgau. \\ (Plates XXXIII.-XXXVIII.)
}

RECENT work has emphasised the importance of the changes in the arteries and glomeruli in the various forms of general disease of the kidney which are not associated with pyogenic or specific organisms.

On the one hand, the work of Jores and his school has again brought into prominence the view, which was originally formulated by Gull and Sutton, that certain forms of contracted kidney are due to primary changes in the small arteries; and on the other hand, the investigations of Löhlein in cases of acute nephritis have emphasised the importance of the glomerular changes which are associated with and differentiate the various forms that occur in this group.

Professor Aschoff therefore suggestıd to me that an investigation of these points should be undertaken. I wish here to express my great indebtedness to him both for this suggestion and for the great help which he has given me throughout the research. I may say that his wide and intimate knowledge of the pathology of the kidney has alone made the investigation possible.

This paper deals especially with the various forms of contracted kidney. It attempts also to trace the course of the glomerular changes in these diseases, and to estimate the value of these changes for the classification of the various forms of kidney disease in harmony with their clinical manifestations. The reconciliation of the clinical and pathological conditions has, throughout, been the chief object of the research.

The material examined has been silected from over two hundred consecutive post-mortems and from the museum specimens of Freiburgin-Breisgau. All kidneys showing contraction or signs of inflammation

\footnotetext{
${ }^{1}$ Received July 30, 1911.
} 
were examined, and also the kidneys of all cases dying of cerebral hæmorrhage. The total number of kidneys investigated was somewhat over sixty. The material was fixed by formol-Müller solution and cut by the freezing method. Routine staining with sudan III., with Weigert's elastic stain, with hæmatoxylin and eosin, and with hæmatoxylin and van Gieson's stain was employed throughout. The main kidney artery also, when possible, was always examined in a similar way.

It is fully recognised that this amount of material is small and hardly justifies generalisation, but it is hoped that it will be possible to continue the investigation on the same lines.

The changes to be dealt with fall into two groups,-those accompanying and consecutive to acute inflammation of the kidney, and those due to alterations which, it will be maintained, are primarily vascular in origin.

\section{The Inflammatory Group.}

The first group, the inflammatory, has been dealt with at length by Löhlein $\left(1906^{1}\right)$. The few cases which have been examined in the present series bear out his views. Two forms of "nephritis" in which the glomerular changes are negligible may first be discussed briefly.

The first is that form which affects the tubules of the kidney only and causes in them changes which are primarily toxic in nature, though varying in aspect with the form of the irritant causing them. Primarily and principally the cells of the convoluted tubules are affected, in all probability owing to the direct poisoning effect of the excretion of the various irritants through the normal channels. Typical causes of this form are organic poisons such as the diphtheria toxin, inorganic poisons such as corrosive sublimate and phosphorus, and also the substances which arise in the course of practically all fevers, and which often give rise to the transient albuminuria so frequently observed at their onset. The effects of the toxæmia of pregnancy on the kidney are also probably to be included in this group. The effects of sublimate poisoning in particular have lately been thoroughly investigated in the human subject by Heinecke $\left(1909^{2}\right)$. He finds that, if the poisoning is recovered from, a complete regeneration of tubular epithelium takes place, the only trace left being some general interstitial thickening between the tubules: the glomeruli escape completely. In other words, complete functional recovery takes place. Ten cases of this type have been examined in this series. Clinically, in these cases, a terminal albuminuria was the only change referable to the kidneys. They could all be referred to causes of the types mentioned above.

The second form is that associated with the earlier stages of scarlet fever, and usually known as acute interstitial nephritis. It is 
characterised by great infiltration of round cells around the large vessels and later around the glomeruli.

It has been fully described by Councilman (18973), Chapman $\left(1906^{4}\right)$, and Reichel $\left(1905^{5}\right)$, who insist on the absence of alteration of the glomeruli here. They only find this form in cases dying in the first fourteen days of the disease, and therefore, probably, it only occurs in cases which prove fatil in the early stages. The true nephritis which leads to permanent changes, according to Chapman, does not arise till the second or third week. Reichel gives an even more exact date, namely, the last four days of the third week.

The first of these two forms, judging from Heinecke's investigations, probably never leads to permanent functional change of the organ; moreover, as far at any rate as the present observations are concerned, there is no evidence that acute interstitial nephritis leads to a chronic form of kidney change. It is possible that this form is always associated with scarlet fever of so severe a degree that recovery does not take place. Professor Aschoff records in his text-book the belief that "genuine Schrumpfniere," which will later be discussed, may have its origin in this form. The evidence to be given later, however, tends rather to the conclusion that "genuine Schrumpfniere" has, as Jores suggests, its origin in a primary disease of the small arteries.

The forms of true acute inflammation of the kidney which probably always lead to recognisable secondary changes have recently been thoroughly investigated by Löhlein.

This observer has endeavoured thrcughout to reconcile the clinical and pathological findings in his cases, and. claims that in the great bulk of them, at any rate, this can be done. In the few cases here investigated it is also claimed that clinical and pachological findings can be reconciled. Löhlein, following the teachings of Langhans and others, lays great stress on the fact that all forms of lasting nephritis are cases of glomerulo-nephritis; that both the form usually known as "large white" kidney and the later "secondary contracted" kidney always show that they have arisen from an original acute glomerulo-nephritis. Here again the present investigations bear out Löhlein's views. He further differentiates true glomernlar nephritis from another form of acute nephritis which has characteristic clinical and pathological features and is always found in association with ulcerative endocarditis. As he considers this form to be due to small embolic infarctions from the heart valves, he calls it "embolische herd-nephritis,"-embolic focal nephritis. This form has been further substantiated by Schottmiller $\left(1910^{6}\right)$, Libman (1910 7), and others in their investigations of ulcerative endocarditis.

To make matters clear, it may be as well to summarise Löhlein's views in tabular form with equivalent nomenclatures (Table I.).

As has already been mentioned, the present cases all group themselves according to this classification. The separation of the ulcerative endocarditis cases from the rest is very important. The non-recognition of this group has caused much of the confusion in attempts at classification of glomerular changes in acute nephritis. For instance, Herringham and Thurstield $\left(1904^{8}\right)$ examined the 
glomerular changes in a series of eases of acute nephritis and failed to make this distinction. Three of their illustrations, however, show changes typical of glomerulo-tubular nephritis; while the other three, from cases of ulcerative endocarditis, show the other form of change.

Table I.

\begin{tabular}{|c|c|c|c|c|c|}
\hline \multicolumn{3}{|c|}{ Löhlein. } & \multirow{2}{*}{ Equivalent Names. } & Aschoff. & \multirow{2}{*}{ Duration of Illness. } \\
\hline & $\begin{array}{r}\text { True Glomer } \\
\text { nephritis }\end{array}$ & culo- & & $\begin{array}{c}\text { Glomerulo-tubular } \\
\text { Nephritis. }\end{array}$ & \\
\hline (A) & Acute & . & $\begin{array}{l}\text { Acute parenchyma- } \\
\text { tous nephritis }\end{array}$ & Acute stage & Days-weeks. \\
\hline$(B)$ & Sub-acute & . & $\begin{array}{l}\text { Large white kidney, } \\
\text { mixed nephritis }\end{array}$ & Reparative stage & Months. \\
\hline$(C)$ & Chronic & . $\quad$. & $\begin{array}{c}\text { Secondary con- } \\
\text { tracted kidney, } \\
\text { small white } \\
\text { kidney }\end{array}$ & Sclerotic stage & Years. \\
\hline$(D)$ & $\begin{array}{l}\text { Embolic } \\
\text { nephritis }\end{array}$ & focal & $\begin{array}{l}\text { Large variegated } \\
\text { kidney }\end{array}$ & $\begin{array}{l}\text { Glomerular neph- } \\
\text { ritis }\end{array}$ & $\begin{array}{l}\text { Coincident with the } \\
\text { endocarditis. }\end{array}$ \\
\hline
\end{tabular}

In the present series the cases of true glomerulo-tubular nephritis will first be described, and then those of the ulcerative endocarditis type.

(a) Only one case of the early acute state of true glomerulonephritis has been obtained. It is probable, as Löhlein suggests, that death in this stage is comparatively rare.

CASE 1.-The patient had been in hospital three times in two years for gastric disease. The urine, examined at intervals on these occasions, was always found to be normal, and was still normal when examined on the seventh day before death.

The next examination on the day before death showed a large quantity of albumin, hyaline and epithelial casts, and in all probability, about four days before death, peritonitis set in owing to the perforation of a gastric ulcer. A terminal broncho-pneumonia was also found post-mortem in addition to the kidney and gastric changes. Here, therefore, the disease was of less than a week's duration.

Macroscopically, the kidney, which had been preserved in "Kaiserling," was greatly swollen and showed many punctiform hæmorrhages over a pale redgrey surface. On section other small red spots were seen. The cortex was increased in width.

Microscopically, as it shows the typical picture described by Löhlein, it may be described in some detail. The glomeruli are all greatly swollen, and have the appearance shown in Plate XXXIII. Fig. 1, which was taken from this case.

The swelling is often so great that the first part of the convoluted tubule has become distended, and the swollen glomerulus is pear-shaped and projects hernia-wise down it. Bowman's capsule has the appearance of being tightly stretched over the glomerulus; otherwise it is normal. The glomerular capillaries are all greatly swollen and are usually distended with blood. In some, however, polymorpho-nuclear leucoeytes predominate over the red cells. The different capillaries are distinguishable from one another, but the cells of their walls are obscured. The latter can often be seen to be greatiy swollen, 
their nuclei are irregular and often appear to be elongated or fragmented. These capillary wall cells contain a considerable amount of diffuse fat, some also show an early stage of hyaline change with little blood content in the Iumen of the capillary. It may here be noted that by hyaline change throughout this paper a homogeneous swelling of cells is only meant; the chemical and therefore the staining properties of the change in various cells are not in any way particularised by the term "hyaline."

The total effect is that the glomerular nuclei are less conspicuous than usual, and the whole structure appears more conf ased. Few leucocytes or round cells are to be seen. The tubules show either a great swelling of their cells which is often so great as to fill the lumen, or are distended and lined with flattened cells ; they contain débris and many casts, usually hyaline. There is also much blood in some tubules which can often be ijraced to a glomerular capsule space. The hæmorrhages are probably all glomerular in origin. The interstitial tissue is generally swollen and odematous, and snows hæmorrhages here and there. The tubules are thus much more separated from one another than usual. The macroscopical swelling is due to this interstitial cedema combined with the tubular swelling.

The kidney arterial system is normal, except that some arteriæ afferentes lying close to the glomeruli often show slight fat change in their intimal layer. This is of interest, as it shows that these arteries participate in the glomerular change, and that the two structures are therefore pathologically closely connected.

The large vessels were normal. The heart showed slight hypertrophy of the right ventricle, and a fresh thrombo-endocarditis of the tricuspid valve.

The points to be emphasised here are the great uniform swelling of the whole glomerulus and the involvement of all glomeruli without exception. According to Löhlein, this general diffuse character of the change is characteristic of this form of nephritis.

(b) Two cases of so-called large white kidney, the reparative stage of glomerulo-tubular nephritis, have been examined. The first case shows typically the characteristic changes, the second presents points of difficulty.

CASE 2.-The patient, a woman æt. 26, was admitted to hospital suffering from typhoid fever: she finally died of this with broncho-pneumonic complications in the fifth week of the disease.

On admission, at about the fourteenth day of disease, the urine contained blood, 3 per mille albumin, and many casts: The amount was not measured. Earlier history of disease was not known. It is, however, probable that the kidney disease was of earlier origin than the beginning of the attack of typhoid fever. The kidney changes point to a durstion of about four months. EEdema was not noted.

Macroscopically, the kidney was very large and swollen, smooth on the surface, and very pale in colour. The cortex was greatly increased. A few sparsely scattered red points were seen on the surface. It, in fact, showed the typical picture of that form commonly known as large white kidney.

Microscopically (Plate XXXIII. Fig. 2), all the glomeruli show alterations. They are large, irregular in shape; contaic little blood, and their structure is confused. There is in all a great nuclear. richness, which takes the form of long nuclei very irregular in shape,-the oval nuclei of the normal glomerulus are always in a minority and in some glomeruli practically absent. Whether these nuclei arise from endothelial cells or whether they are proliferated irregularly shaped epithelial cells will not be discussed here. It may, however, be stated that, for reasons appearing later, it is not believed that they have 
origin in the proliferation of connective tissue in the glomerulus itself. In some glomeruli the capillaries appear widely separated, probably owing to epithelial desquamation. Some show characteristic hyaline degeneration; this stains brown with van Gieson's stain and bright pink with easin. These hyaline capillaries are swollen and homogeneous-looking and contain few neclei. Degenerate capillaries are often blended with the capsule wall, so that the glomerulus becomes adherent in one or more places. When a complete eapillary degeneration is present the whole glomerulus is blended with the capsule; it then contains few nuclei and often shows considerable fat change.

The capsule space of many glomeruli is filled with cells, which are either desquamated glomerular epithelial cells or proliferated capsule-lining cells. These cells often show fatty degeneration; they are therefore in all probability mostly desquamated epithelial cells. The fibrous tissue of the capsule has increased in all the glomeruli. The adherence of the glomerulus and capsule can be seen in all grades, from a very slight adherence at one point to many extensive adhesions, and finally in the most degenerate ones to the complete adherence already described. The fibrous tissue of the capsule is seen to be invading the glomerulus at the points of adhesion, this invading tissue showing up red in van Gieson stained specimens. The tubules are in various stages of swelling, degeneration, and desquamation of their lining cells. They contain casts of various descriptions, and also very occasionally red blood cells.

The interstitial tissue is diffusely and generally increased, the increase consisting of new fibrous tissue cells and fibres. There is also considerable oedema yet present; round-celled infiltration is present in places. Intertubular capillaries are inconspicuous, and only occasionally contain blood. Some interstitial cells often contain fat droplets. These latter cells are in part, according to present views, endothelial cells of the lymph spaces (1909 $\left.{ }^{9}\right)$.

The arterial system of the kidney is normal except for an occasional slight fat change in the intima of the arteria afferens where it enters the glomerulus.

The main artery of the kidney shows a few patches of intimal thickening staining poorly with elastic stain. This is evidence of early senile arteriosclerotic change, as Hallenberger $\left(1906^{10}\right)$ and others have shown.

The heart was slightly hypertrophied on the right side, not on the left. Old inflammation of the pleura and old pericarditis gave a sufficient explanation of this slight hypertrophy. The absence of hypertrophy of the left ventricle may have been due partly to the coincident attack of typhoid fever, but perhaps three to four months is too short a time for it to develop. It has always been found in cases of the later more chronic class.

The points to be emphasised here, as far as the glomeruli are concerned, are, again, the involvement of all the glomeruli and their variable amount of adherence to the capsule.

In the second case of this group (Case 3) the kidney was macroscopically similar in appearance. Microscopically, however, it showed interesting differences.

The clinical history and anatomical findings are confusing.

CASE 3.--The patient, a man æt. 39 , had suffered at some earlier unknown date from acute rheumatism and heart disease. He was also addicted to alcohol in quantity. For six months before death he had had sickness, abdominal pain, and epistaxis at intervals. His mental condition was not clear for the last few weeks before his death. Albumin and sugar were found in the urine by his private doctor at the beginning of this last illness. He was brought to hospital in a comatose state. The urine contained $\frac{1}{2}$ per mille albumin, red blood cells and casts. The amount was not measured. $\mathrm{He}$ became more comatose, and died four days later. 
Post-mortem, his heart showed scarring of the mitral valve and old pericarditis. Both ventricles were greatly dilated. The heart muscle showed fatty degeneration. The liver was markedly cirrhotic, and the lungs showed bronchiectasis and old tuberculosis. There was considerable cedema of the legs and a hæmorrhagic ascites.

The cause of death in this case was therefore not uncomplicated kidney disease. The condition of the heart, lung, and liver probably had also at least as much to do with it.

Microscopically, the kidney was romarkable for the large number of normal glomeruli present. Only a small proportion were changed. The altered ones show similar changes to thcse seen in Case 2, some being totally degenerate and having complete adherence to the capsule, others having points of adhesion with partial hyaline change of their capillaries. The tubules and interstitial tissue had similar changes to those occurring in Case 2.

The kidney arteries showed no changes.

In this case there are enough glomerular changes to make it clear that the original disease was a glomerulo-nephritis.

It is, however, impossible to say whether all the glomeruli were originally affected and had mostly jecovered, or whether only a few were originally involved. If the former is the case, this case belongs to the present group. If the latter, it may be an example of the chronic stage of the embolic focal nephritis type, dating from the heart disease of unknown date. The condition of the heart, however, shows the effects of an earlier simple rheumatic endocarditis rather than the possibility of a healed vilcerative condition. The former explanation must therefore be advanced as the more probable. There is nothing impossible in the view that in a mild case recovery of the greater part of the glomeruli may take place without adhesion and consequent fibrosis.

(c) Six cases of secondary contracted kidney, the sclerotic stage of glomerulo-tubular nephritis, have been collected. Five of these died of uræmia, a history in the sixth case was not obtainable.

The ages of these patients are seen in Table II. (p. 312). They all lie between 20 and 40 years. Where history of the probable date of onset was obtainable it showed that the disease had lasted over a year, with the usual urine changes and other symptoms. Polyuria, much albumin, casts, and, at times, blood were present in these cases. The polyuria was present up to the onset of the symptoms of coma, when the urine diminished in quantity. Finally, death in coma occurred with great diminution in the amount of the urine.

The blood pressure was always high, between 160 to $220 \mathrm{~mm}$. in the four cases in which it had been examined.

The final uræmic condition was in three cases accompanied by a. fresh pericarditis. Retinitis albuminurica was present in all but two cases, in which no notes on the subject were obtainable.

Macroscopically, the kidneys were all uniformly contracted and smaller than normal. The capsule was adherent and the surface rather coarsely granular. They varied considerably in colour, from a yellow-white in Case 9 to a deep red in Case 7. The common name for this group, small white 
kidney, is, most certainly, a very erroneous one as descriptive of this group, and the sooner it is given up the better it will be for the recognition of this condition. The colour of a contracted kidney is little guide to its pathological significance. In this connection Dixon Mann's (1895'1l) case may be quoted. He was able to watch his patient from the beginning of the illness to the final issue-death from uræmia-many years later. He found, pose mortem, a small red contracted kidney. The microscopical examination by Delépine showed it to belong to the group of secondary contracted kidneys, the sclerotic stage of glomerulo-tubular nephritis.

To turn to the microscopical appearances of the kidney in this group, as seen in Plate XXXIV. Fig. 4 , the glomeruli are in great part destroyed and are seen as homogeneous-looking hyaline nodules completely blended with their capsule. In contrast to forms to be described later under the vascular group of contracted kidneys, they are fairly large and their boundary cannot be differentiated. They take a uniform pink colour with van Gieson's stain, no differentiation being by this means obtained between capsule and glomerulus. They contain few or no nuclei. They often take considerable fat stain and show elastic fibres in their capsule. Of some only the faintest trace can be seen, as they have become so greatly blended with the surrounding selerotic tissue.

Other glomeruli are still preserved to a greater or less extent, but these all show changes which, it is claimed, are characteristic of the sclerotic glomerulotubular form. Fig. 3 is taken from Case 5 in this group. Following the changes seen in the reparative stage (the stage of the large white kidney) the glomerular capillaries still left have now recovered and again show the nuclear appearances seen in a normal glomerulus. That is to say, the increase of long and irregular nuclei has practically disappeared, showing incidentally that these did not belong to new connective-tissue cells; the oval nuclei of the normal glomerulus again greatly predominate. The characteristic change is seen in the capsule space. The points of adhesion described in the second or reparative stage are still to be seen, but in the intervening remains of the capsule space a regeneration of epithelium has taken place. Owing to the previous acute stages the capiliaries have mostly become adherent to one another; the regenerating epithelium, which probably arises from the capsule epithelium, grows therefore over these adherent glomerular capillaries, the outer wall of the capsule space and also any strands of connective tissue which are left stretching across this space. This growth of new epithelium over all these structures often leads to a great aggregation of regular epithelial sells between the glomerulus and the fibrous tissue of the capsule, every avail. able space becoming clothed with it (Plate XXXIV. Fig. $4(a)$ ). This cellular filling of the capsular space is essentially different from the filling with desquamated cells in the earlier stages. In all six cases glomeruli answering to the above description have been found. Some of the practically destroyed glomeruli show also a thin remains of capsule space with a new epithelial elothing, as is seen in Plate XXXIV. Fig. $4(b)$. Many partially and totally destroyed glomeruli show fat staining. This type of glomerulus with regenerated epithelium covering the remains of the capsule space has never been seen in the other forms of contracted kidney examined.

The tubules have been to a great extent destroyed. Those still present lie radially disposed; they are greatly dilated, and are lined by a flat epithelium which often takes a faint fat stain. They often have considerable lumen contents of various kinds. Around these dilated tubules the interstitial tissue is comparatively slight in comparison with that in the rest of the kidney substance. The interstitial tissue is very greatly increased in the region of destroyed glomeruli and tubules, and frequently shows considerable roundcelled infiltration. Scattered cells may be seen in it, taking a deep red with fat stain, which may be the final remains of degenerated tubules. There is 
also fat in the connective-tissue cells themselves. The general appearance is seen in Plate XXXIV. Fig. 4, taken from Case 5.

The condition of the heart and arterial system showed some variations in different cases, but agreed in the main features. The afferent arteries in all but Case 7 showed fat in their walls when connected with glomeruli in which there was fat change. The elastic layer was prominent in these and also throughout the kidney arterial system, the change being hypertrophic. In all, however, a greater or less thickening of a true arterio-sclerotic type was present here and there throughout the arterial system. This true degenerative arterio-sclerotic change increases with the age of the patient; it was especially marked in Case 8 , this patient being 39 years of age.

The main kidney artery in the four cases in which it was obtained also showed distinct arterio-sclerotic changes. The aorta, on the other hand, except in Case 8, was always uniformly smooth on the surface, though its. wall appeared thickened. This change is hypertrophic in nature. In Case 8 there was, in addition, slight atheromatous change present.

The heart in all cases was hypertrophied, the left ventricle being especially involved. In four cases the hypertrophy was great, the heart weighing over 500 grms. The heart valves were normal in every case. It appears, therefore, that secondary contracted kidney is always accompanied by heart hypertrophy, often of great degree; and also by a hypertrophy of the aortic wall in consonance with the heart change. The renal vessels also show this hypertrophy in their elastic coats, but in addition some degenerative changes comparable with the arterio-sclerosis occurring in the later periods of life. In Case 8, 39 years of age, near the limit when senile arterio-sclerotic changes may occur normally $\left(1910^{10.12}\right.$, arterio-sclerotic changes of severe degree are present in the renal arteries and to some extent in the aorta. The kidney disease and consequent high blood pressure have caused their appearance earlier than usual.

The glomeruli in these three stages of glomerulo-tubular nephritis therefore show a consecutive series of changes, each of which logically follows from that of the previous stage. The final form reached by a partially destroyed glomerulus in the secondary contracted stage is diagnostic of this form of contracted kidney.

(d) The three cases of embolic focal nephritis which have been examined may now be discussed :

In CASE 10 no clinical history could be obtained.

CASE 11 had a history of ulcerative endocarditis of one month's duration. The patient was a man æt. 70, with ulcerative disease of the aortic valves. Massive arterio-sclerosis of the aorta and large vessels was also present. As regards kidney symptoms, the urine contained a little albumin, some casts, and throughout a considerable amount of blood: the latter was never absent. The daily amount was small, between 700 and 1200 c.c. Irregular fever was present throughout the illness. No odema was ever present.

$\mathrm{C}_{\text {ASE }}$ 12. - There was a very detailed history of ulcerative endocarditis lasting six months and terminating with embolism of the right Sylvian artery. The temperature was irregularly raised throughout. The urine showed a varying but small amount of albumin, under 1 per mille, various casts, and always blood in some quantity. The amount of urine was about normal. Edema was never present.

These two cases show, therefore, a elinical point insisted upon by Löhlein $\left(1910^{1}\right)$, that this form of nephritis is essentially hæmorrhagic in character. The urine is not greatly increased in quantity and 
contains little albumin. This can be made to correspond with the microscopical findings.

In all three cases the kidneys were macroscopically very similar in appearance. They were somewhat larger than normal, though not very greatly enlarged. The surface was red grey in colour, with an enormous number of hæmorrhagic points scattered thickly over it. It was smooth in Cases 10 and 12 , but in Case 11 it was roughened and in places the capsule was adherent.

Microscopically (Plate XXXV. Fig. 5), the glomeruli are altered in a very characteristic manner. The alteration affects a greater or less number in the different cases. In all, however, glomeruli can be found which are normal in appearance; in Case 10 at least half are thus unchanged. The change therefore affects only some glomeruli. In these glomeruli, again, only some capillaries are altered, often only one or two; the rest of the capillaries show no changes. The altered capillaries are swollen and often contain a fibrinous exudate which stains yellow-brown with van Gieson. The swollen capillary walls take a pink stain. The blending of these two changes often causes the altered capillary to have a brownish appearance. This fibrinous yellow staining substance may also lie outside the glomerulus in the capsule space; in some examples it extends round the sound part of the glomerulus and also for some distance into the tubule. It is frequently mixed with red blood cells. In addition there is also a leucocytic infiltration of the affected part of the glomerulus and of the surrounding tissue. This leucoeytic infiltration is not bounded by any glomerular structures, but involves also the capsule and the neighbouring tissues, as is seen in Plate XXXV. Fig. 5, taken from Case 11. The capsule space over the altered capillaries is often filled with epithelial cells which are partly desquamated glomerular epithelium, but also possibly have arisen from the capsular epithelium, as mitoses have been observed in them. The diseased capillaries are thus blended with the overlying part of the capsule, partly by the exudate and partly by these epithelial cells. The difference between the capsular changes over the diseased and sound capillaries of the glomerulus is very striking, the capsule over the latter being usually quite unchanged. The localisation of the leucocytic infiltration may again be emphasised, and the fact that it has no regard to glomerular or other structural boundaries. The appearance is, in fact, like a localised early abscess of very minute dimensions.

In the long-standing Case 12 the glomeruli show a later development of the condition. The fibrin is now no longer conspicuous; the leucocytic infiltration has, to a great extent, disappeared, and given place to a roundcelled one. The different condition of the sound and altered capillaries in single glomeruli is again very conspicuous. The degenerate capillaries and the capsule have become completely blended, and take a uniform pinkish tinge with van Gieson's stain. Some few glomeruli are totally destroyed and are completely blended with the capsule.

These appearances are consonant with Löhlein's view, that they are directly due to embolic infective material from the diseased heart valves, which, being finely divided, is carried to, and lodges in, one or more capillaries of the glomerular tuft. A large number of glomeruli show blood in their capsule space with or without fibrinous exudate. This explains why this is clinically a hæmorrhagic type.

The tubules are not greatly altered considering the great glomerular changes. Some show swelling of the lining cells and occasional desquamation, others dilatation, with at times débris in the lumen, but much more frequently blood. Few casts are to be seen.

The interstitial tissue is not greatly increased, though this varies in different places. Where there is increase there is usually considerable cell 
infiltration, which is mainly leucocytic in character; in the long-standing Case 11, however, it often contains many round cells. These areas of leucocytic infiltration, as has already been stated, are usually in connection with glomeruli. The hæmorrhages in the tubules are usually, and probably always, traceable to glomeruli.

It may be mentioned that in Case 11 , the patient being 70 years of age, destroyed glomeruli of a different type were also found, and also interstitial changes round these. They are to be referred to coincident changes shortly to be described as typical of the senile arterio-sclerotic type of kidney ehange. In this case there was great arterio-sclerosis of the aorta and other arteries. In the other two cases the arteries were normal throughout the body.

In this form of kidney change, therefore, only some capillaries in some glomeruli are affected. The changes in themselves also differ from the general glomerulo-tubular type by the presence of the marked fibrinous exudate and the great leucocytic infiltration. The tubules and interstitial tissue are not very greatly altered; this affords the explanation of the comparatively small macroscopical swelling. The present three cases all accompanied ulcerative endocarditis of the heart valves.

The kidney changes may therefore be due to embolic causes, as Löhlein suggests. It has not been possible to get direct evidence of this in the present series, blood cultures when taken both ante- and postmortem having proved sterile. However, the work of Horder (1909 ${ }^{13}$ ), Lenharz $\left(1910^{14}\right)$, Libman $\left(1910^{7}\right)$, and others has substantiated the fact that ulcerative endocarditis may be looked upon as a form of long-lasting septicæmia with the chief focus in the heart valves. It is easy to see that a constant embolic infection is extremely probable in such cases. The kidney appearances themselves also are in harmony with this idea.

This form of kidney change can, therefore, both clinically and anatomically, be separated from the general glomerulo-tubular form.

It is improbable that cases of so-called subacute ulcerative endocarditis ever definitely recover, therefore a secondary contracted kidney with this as the primary form of disease is not to be expected. Case 3, as has already been stated, may possibly be a case of this type, as healed endocarditis was undoubtedly present; however, the probabilities point to its inclusion in the general glomerulo-tubular type. If a secondary kidney change can thus arise it would probably be very hard to distinguish it from the secondary form of glomerulotubular nephritis if the primary change in the glomeruli had been extensive. As Löhlein has pointed out, a parallel may be drawn in the simulation of lobar pneumonia by a confluent bronchopneumonia.

As regards other views and the earlier history of the classification of acute nephritic changes, a full summary with the literature will be found in Löhlein's $\left(1910^{15}\right)$, general review of the present position of the subject. 


\section{The Vascular Group.}

Those changes which are due to vascular disease also fall into two sub-groups. In the first are those which are due to the very slow alteration of the organ which senile arterio-sclerosis produces. In the second are those due to changes which affect especially the small arteries and arterioles of various organs of the body. These two sub-groups are differentiated by different age incidence and also by their verry different clinical significance.

The first type has only been found in the present series in cases over 50 years of age, while the second has occurred at an earlier period of life, between the ages of 30 and 50 in all cases but one. The condition of the heart is very different in the two groups: in the first, the heart is seldom enlarged, and never to any great extent unless valvular disease is also present; in the second, the heart is always greatly hypertrophied. These and other differences will be further dwelt upon in the detailed description of the two forms.

Senile arterio-sclerosis was first mentioned by Ziegler as a cause of fibrosis and contraction of the kidney. Since then it has become generally recognised as a cause of kidney contraction in the later stages of life.

Recent papers by Herxheimer (1909 $\left.{ }^{16}\right)$, and Fahr (1909 ${ }^{17}$ ) show with what frequency senile arterio-sclerosis, accompanied by chronic contraction of the kidney, occurs in later life. Both changes are present to a greater or less extent almost without exception in old people. Twenty cases, the details of which are given in Table III. (p. 314), have been examined in the present series. In none of these have clinical signs of kidney disease been observed with the exception of some polyuria, and at times a slight albuminuria. In other words, this form of kidney change is an incidental process occurring in the later periods of life, and clinically is of little significance. Fahr (1909 ${ }^{17}$ ) also emphasises these points in the paper mentioned above.

The macroscopical changes in this form of kidney are better left until the microscopical appearances have been described.

The vascular changes in the large vessels of the body and the heart may first be referred to. It is significant that in all the cases in Table III. senile arterio-sclerosis was always present in the aorta and was often very marked. This change was also always present in the main artery of the kidney, and can in every case be traced into the smaller arteries of the organ in any regions where glomerular destruction and fibrosis are present. The extension of the change into the small kidney arteries is not always proportional to the change in the aorta. In Case 17, for instance, the aorta was very greatly diseased, while the small arteries of the kidney were very little altered; the amount of kidney change was very slight.

The amount of kidney change, though therefore not dependent on the change in the aorta, is directly dependent on the condition of the small arteries. That is to say, the spread of the arterio-sclerotic condition into the arteriæ interlobulares and afferentes directly determines the amount of kidney 
destruction. The condition of the heart may also be emphasised. With the exception of one case in which with very severe change in the kidney a slight hypertrophy of the left ventricle was found, the only cases in which the heart was enlarged can be otherwise explained. In Case 13, where the change in the kidney was very slight, hypertrophy of the prostate with some hydronephrosis on both sides gave a sufficient explanation. In Cases 26 and 27 disease of the aortic valve was present. In Case 31 chronic pericarditis was present. In all the remaining cases the heart was either normal or reduced in size.

The microscopical changes in the kidney may now be dealt with. These centre round the destruction of the glomeruli. This destruction, even with great contraction of the organ, only affects a comparatively small percentage of the glomeruli, the remainder are normal in appearance, a condition in marked contrast to that in secondary contracted kindey. Two forms of glomerular alterations are met with. In the one form the glomerulus is shrunken, often to half the normal size, and surrounded by a thickened eapsule; the capillaries though collapsed are not otherwise altered. In the other form the glomerulus is completely degenerated and has fused with the thickened capsule. It is very small. This latter form stains very characteristically with van Gieson's stain. The degenerate glomerulus takes a brownish tinge, while the capsule thickening takes a deep crimson (Plate XXXV. Fig. 6). Intermediate forms between these are also seen with the capsule commencing to take the deep crimson stain. The first type of shrunken glomerulus with thickened capsule has been traced through serial sections in Case 23, which showed a convenient degree of change. These glomeruli are found to be always connected with an interlobular artery which shows with its afferent branches a considerable degree of irregular arterio-sclerotic intimal thickening. Total occlusion of the arteries was not found at this stage, though the lumen was often much narrowed (Plate XXXVI. Fig. 7). It was also found that those glomeruli with longer arteriæ afferentes were the first to show the changes, while those with shorter arteriæ afferentes, lying close to the interlobularis, were still normal in appearance. The tubule belonging to such a glomerulus was found to be extremely atrophic, the lining cells being extremely degenerate and often consisting of little more than an irregular nucleus (Plate XXXVI. Fig. 8). The two figures 7 and 8 are taken from the same glomerulus. The interstitial fibrous increase is always grouped round the atrophic tubule and glomerulus, and does not extend among the normal tubules belonging to sound glomeruli which surround the atrophic patch. Some of the capillaries in the neighbourhood of the patch are often very distended and full of blood, though in the path itself they are not to be made out. At this stage there is a little round-celled infiltration; the few round cells present, as seen in Plate XXXVI. Fig. 8, are always grouped round the atrophic tubules. Compression at the neck of the glomerulus, as described by Herxheimer $\left(1909^{16}\right)$, was never observed.

The explanation of this condition seems to be the following. Owing to the irregular alteration of the small vessels of the kidney, which is of very different degree in different arteriæ interlobulares, and owing to the lack of heart hypertrophy and the bad conduction of the pulse wave by the diseased arteries, the pressure of the circulation through these more greatly altered channels falls below that necessary for excretion by the glomeruli. This requisite pressure is considerable. Starling $\left(1899^{18}\right)$ gives it as $30 \mathrm{~mm}$. of mercury. This failure of excretion by certain glomeruli is easily compensated for by the glomeruli supplied by better-preserved arteries. The want of pressure in the glomeruli is brought about partly in consequence of the narrowing of the lumen, but also by the inefficiency of the vascular

21-Ji. OF PatH.-voL, xvi. 
apparatus to drive blood through the cliseased vessels. The glomerulus then loses its function and also shrinks, as the normal pressure which keeps it distended and in function has been lost.

The tubule in connection with it loses both a large part of its blood supply, which comes from the glomerular arteria efferens, and also its function. The lining cells therefore become atrophic and degenerate, and the whole tubule shrinks enormously. This causes a concentration of the connective tissue which normally lies round the tubule and the glomerulus. How great this concentration will be is clear when it is remembered that the diminution of the glomerulus, so that its diameter is halved, must cause the capsular connective tissue to become four times as thick, as the latter is spread over the surface of a sphere, and is proportional to the square of its diameter. At the same time a reactive cedema causes swelling of this concentrated connective tissue, and also gives rise to a secondary proliferation of its cells. The fibrous nodule is therefore caused partly by a concentration of fibrous tissue and partly by a secondary connective-tissue increase. It may be again insisted on that a fibrous or other strangulation of the neck of the glomerulus has never been observed.

The proliferation of the capsular connective tissue now leads to the appearance of a substance in it staining deeply crimson with van Gieson's stain. This often first appears in the neighbourhood of the neck of the glomerulus. This appearance is due to a hyaline change in the connective-tissue fibres of the capsule. The term lyyaline, as has been previously explained, is merely used to signify a homogeneous, probably degenerative, swelling of any interstitial tissue. The glomerulus itself also slowly degenerates, its degenerate cells giving, first, a light pinkish stain with van Gieson's stain, but later, a characteristic brown colour. The degenerate glomerulus and capsule fuse together, owing mainly to the swelling of the capsular sulstance, which moulds itself to the remains of the glomerulus. The characteristic picture of a destroyed arterio-sclerotic glomerulus, as seen in Plate XXXV. Fig. 6, has thus arisen. New elastic tissue also, as first described by Aschoff and Gaylord (1902 ${ }^{19}$ ), and since corroborated by Herxheimer $\left(1909^{16}\right)$, usually appears at this stage in the outer zone of the thickened capsule outside the deep red zone. The tubule of the glomerulus has now completely disappeared. The degeneration also gives rise to a low form of inflammatory change which is characterised by round-celled infiltration. This is seldom of high degrce unless several degenerated areas lie together. In the latter case it may assume considerable intensity.

Later changes also occur, and the destroyed glomerulus is invaded and replaced by granulation tissue. The deep crimson capsular thickening then appears to be sickle-shaped or irregular, and to lie in scar tissue which has no longer any resemblance to kidney tissue. It is the last trace of the previously existing glomerulo-tubular system. 
This capsule remnant often shows marked fatty change, and may ultimately disappear. The whole process of degeneration, followed by a low form of inflammation, is similar to arterio-sclerotic changes in other parts of the body, such as the senile osteo-arthritic change.

The distribution of the altered glomeruli follows, as has been mentioned already, the distribution of certain arteries. The totally destroyed glomeruli belong to arteriæ interlobulares whose lumen is occluded, or else lie in the peripheral zone of a not yet occluded artery. The nodules of contraction therefore lie along the course of the interlobulares, and lead to a radial contraction of the kidney substance. In any given section destroyed glomeruli may appear not to lie in groups but to be scattered irregularly. Serial sections, however, show that they are always related to arterial distribution. The portion of any artery glomerulus system most affected is naturally the most peripheral part under the capsule. The destroyed areas therefore tend to exhibit a cone shape with the base to the surface. This is well seen in the stages of slighter contraction. When the contraction is great the distribution of the atrophic changes in any particular section is diffuse.

The general distribution of shrinkage through the kidney thus depends on the relative amount of change in the interlobular arteries. If certain groups of these are much more affected than others, the gross contraction of the kidney will be very irregular. The surface will show deep scar-like pittings which are reminiscent of old areas of infarction. Case 29 showed this form to a very marked degree. If, however, the condition is more uniformly spread through the interlobulares a much more general contraction will take place, and the more usual form of finely granular contracted kidney will occur. Case 30 was a typical example of this type. This contraction may, in some cases, be very great. In Case 30 the kidney only measured $3 \frac{1}{4} \times 1 \frac{1}{2} \times 1 \frac{3}{4}$ inches. All varieties between these extremes occur.

Cysts are of frequent occurrence in this form of contracted kidney; for instance, many were present in Case 32. These are in all probability congenital in origin, as Ruckert $\left(1903^{20}\right)$ suggests. Their more gross development may possibly be dependent on the fibrotic change of the arterio-sclerotic contracted kidney. No evidence that they are dependent on capsular or tubular dilatation has been found; on the contrary, cysts have frequently been seen lying in normal tissue. It is probable that cystic spaces are present in all kidneys to some extent. When they lie in the medulla they lead to a characteristic form of cortical contraction similar to that seen in hydronephrotic kidneys. This change, however, does not come within the scope of this paper.

In connection with the arterio-sclerotic change, one other case may be referred to, a case with the scar of an old infarct of the kidney. Here in 
the necrotic area shrunken remains of glomeruli are seen lying in the necrotic tubular tissue. In these no indication of thickening of Bowman's capsule is to be seen. However, in the surrounding tissue characteristic arterio-sclerotic glomerular destruction has occurred. The glomeruli have thickened capsules and the appearances described above. The arteries at the base of the infarct, owing to the cutting off of most of their branches, have undergone secondary fibrotic changes spreading centrally. This has caused a secondary arteriosclerosis of their other neighbouring branches, and has thus given rise to a local arterio-sclerotic change of the surrounding kidney substance.

This arterio-sclerotic form of kidney disease is therefore due to atrophy following inefficiency of circulation through the diseased arteriæ interlobulares and afferentes, and consequent fibrosis following this.

The second group of kidney changes of vascular origin is that group which is known in Germany as "reine" or "genuine Schrumpfniere," but has not been clearly differentiated in this country from other forms. In Adami's "Pathology" (vol. ii.) the name primary contracted kidney has been adopted. It has also been called the red contracted kidney. However, seeing that both the other forms already described can also be red as well as contracted, this name is in no way distinctive and the sooner it is abandoned the better. As a matter of fact, the senile arterio-sclerotic kidney is much more regularly a red contracted kidney than is this form, whose coarse granulations are often very pale in colour, as in Case 33. In general features the microscopical changes are comparable to those in the arterio-sclerotic form, but certain characteristic features enable the form under discussion to be distinguished from this. Clinically also it belongs to a very different and much more important class of general arterial change.

The first description of this class was given in 1872 by Gull and Sutton $\left(1872^{21}\right)$ in their classical paper. They insisted that the changes were initially dependent on the alterations in the small arteries of the kidney, and also, a very important point, that this small artery change is by no means confined to the kidney, but is also conspicuous in other organs, notably the brain and spleen. In fact, they used the small arteries of the brain, mainly, as their criterion of artery change in their investigations. As, however, they confused this group with both secondary contracted kidney and also with the senile arterio-sclerotic form, their results as a whole are confused. They also did not clearly recognise the portion of the artery wall which is mainly affected; they held that the main thickening was in the adventitia, that it was diffuse and spread into the surrounding tissues, thus causing local fibrosis round the arteries. They named the process arterio-capillary fibrosis. The change was, however, accurately observed but wrongly described by Johnson (1872 ${ }^{22}$ ). His pictures show that the internal longitudinal muscular layer, which he describes as being greatly hypertrophied, is really the greatly thickened intimal layer. 
This view of Gull and Sutton's has of late been revived by Jores and Prym (1904 $\left.{ }^{23}\right)$. They hold that the small artery change is a true arterio-sclerotic process, and is not a special change peculiar to this form of kidney change as some other observers have maintained. They insist also that the small artery change in the kidney is part of a general small artery change affecting many organs. The present investigations bear out this view. The small artery change in the brain is especially important, as it frequently leads to cerebral hæmorrhage or softening; in fact, this cerebral change is the direct cause of death in many cases of this class. Attention may again be drawn to the age incidence of this form. It occurs much earlier in life than does the senile arterio-sclerotic form. All the present cases but one, as can be seen in Table IV. (p. 316), lie between the ages of 34 and 50 ,-the middle period of life.

The general clinical picture is often very complex, but certain conditions directly dependent on the small artery change are always present. One of the most important of these is the very great heart hypertrophy which affects the left ventricle especially. The occurrence of this throughout the series is seen in Table IV. This is again in marked contrast to the cases of senile arterio-sclerotic kidney, where heart hypertrophy of any extent is not present except with coincident valvular disease.

Another point of great importance is the great increase in the blood pressure. In cases in the table where this has been examined it was always found to be over 200 . Further elinical details will be found in the separate protocols. The condition of the urine, for instance, was found to vary considerably in different cases, and is therefore most conveniently described separately.

Turning to the arterial system, the aorta in five cases showed a normal smooth wall, while in the other four only the very slightest change was present,- - namely, a few fatty flecks under a smooth endothelial lining. The renal artery, however, showed an amount of definite arterio-sclerotic change, which varied in the different cases but was always present. The arches also showed a variable but always present arterio-sclerotic change. The conspicuous and important change in all this group was, however, the extreme thickening of the intima of the smallest arteries of the kidney, the arteriæ afferentes especially. The interlobulares also were greatly affected. This thickening was of such extreme degree that often the lumen of the artery appeared totally oceluded. At the same time these enormously thickened arterial walls contained a large amount of fat, giving a most characteristic picture to sections stained with fat stain. This fat change was first described by Jores $\left(1904{ }^{23}\right)$. These small arteries are most conspicuous over the whole section, showing up as bright red rings (Plate XXXVII. Fig. 9). Elastic tissue is also highly developed in all these arteries, both large and small; it can be fairly regular in a 
very thick arteriole. This thickening is so very much greater than that in the other forms of contracted kidney-namely, the senile arterio-sclerotic and secondary-that it at once distinguishes this group. The others, it is true, have thickening and fat change in the walls of the small arteries, but the condition of these vessels does not dominate the picture as in the group under discussion. It is probable, from the evidence of serial sections cut by the freezing method and stained for fat, that in this form complete occlusion of its vessel is necessary to cause the destruction of a glomerulus. This is understandable as in this case, in contrast to the senile arterio-sclerotic condition, there is, owing to the great heart hypertrophy, a most efficient propulsion of blood into every artery that is yet permeable. Additional evidence of circulatory efficiency is furnished by the high blood pressure.

The cases examined have been separated into three groups: $(a)$ Those with marked kidney change; $(b)$ those in which kidney change was macroscopically unnoticeable; $(c)$ two cases whose arterial changes agree with this group, but whose glomerular alterations are of a very peculiar type.

(a) The condition found in Case 33 will first be described, as these are typical of group $(\alpha)$. Plate XXXVII.Fig. 9 is taken from this case.

The patient, it woman wt. 37, had suffered with "heart disease" for about a year previously. Sickness, headache, and giddiness accompanied this. She finally came to hospital owing to difficulty in vision, probably owing to albuminuric retinitis. This was a week before death. On admission there was general œdema of the eyelids, abdomen, and legs. The heart was much enlarged, with a double murmur at the apex. The urine on admission showed the presence of blood, albumin $2 \frac{1}{2}$ per mille, and granular casts. Blood pressure, 228.

The urine progressively diminished from 2000 to 800 c.c., and the albumin progressively increased from $2 \frac{1}{2}$ to $8 \frac{1}{4}$ per mille during the days in hospital.

Post-mortem.-The heart was found greatly hypertrophied with marked mitral stenosis, the valve only admitting one finger. No dilatation of the ventricles was found. The aorta was normal save for a few very small yellow Hecks; its wall was hypertrophic.

The brain showed great arterio-sclerotic changes in both large and small arteries, and fresh hæmorrhages into both right and left nucleus lentiformis. There were also many small old hæmorrhages in the basal ganglia and the right centrum semiovale. The fresh hæmorrhages were the probable cause of death. The oedema can be explained by the marked mitral stenosis. The urine is typical of a terminal condition of stasis due to back pressure.

Macroscopically, the kidney is considerably contracted, and shows extremely coarse nodular granulations on its surface. The nodnles themselves are pale, but the contracted tissue between them is dark grey red in colour. The cortex is much reduced and confused with the medulla. The pelvic fat is increased.

Microscopically, the general appearance is seen in Plate XXXVII. Fig. 9. The outstanding feature is the extreme intimal thickening of the small arteries, both interlobulares and afferentes. These often take some elastic stain in their 
outer part, and frequently show an extreme grade of fatty change. The lumen is often completely occluded.

The glomeruli are of four types. First, those which are normal in structure but are often of large size compared with those of a normal kidney. They have a slight excess of nuclei of not quite the usual form, but show no sign of true inflammatory change. These are probably hypertrophic; they are very numerous.

Secondly, glomeruli whose cupsule is often thickened to a great degree; the glomeruli themselves are much shrunken but lie free in the capsule space.

Thirdly, glomeruli totally destroyed and small, with the characteristic appearance and staining properties seen in the senile arterio-sclerotic degenerate glomerulus. The red and brown differentiation with van Gieson is conspicuous.

Fourthly, glomeruli which may have some thickening of the capsule, but which seem to have suddenly undergone necrosis. These are often of large size. They take a darkish grey-blue stain in hæmatoxylin and eosin specimens, and show only granular remains of nuclei. With hæmatoxylin and van Gieson's stain they also appear bluish-grey in colour. They are quite distinct from their capsule. In some of the smaller otherwise normal-looking glomeruli peripheral parts often take considerable fat stain ; these parts also look somewhat swollen and hyaline in sections stained in other ways. The destroyed glomeruli also often take a marked diffuse fat stain. New elastic tissue is often present in their capsule. The altered glomeruli tend to lie in groups in greatly increased connective tissue.

The tubules in regions of altered glomeruli are very small and atrophic, and lie in a greatly increased connective tissue.

These areas alternate with fairly large areas of distended but otherwise normally distributed tubules with little or no interstitial increase; the tubular lining cells are, however, swollen and altered in places. From serial sections it is seen that the atrophic tubules, as in the senile arterio-sclerotic form, belong to shrunken glomeruli with thick capsules. The totally destroyed glomeruli have no recognisable tubules. The large normal glomeruli, including those having the peripheral fat change, belong to the more normal dilated tubules. The interstitial increase, as has already been stated, is very patchy in its distribution, and lies around the altered glomeruli and tubules. It often shows a very marked round-celled infiltration and also a diffuse fat change. The shrunken and destroyed glomeruli are therefore very similar to those seen in the senile arterio-sclerotic form; the reactional changes are, however, much more pronounced. The distribution is also similar, and can be explained on similar lines by a cutting off of the blood supply and loss of function of the glomeruli owing to the great thickening of the arteries.

The necrotic glomeruli in all probability arise by a sudden total occlusion of their supplying arteries.

The whole condition can therefore be explained on the same lines as the senile arterio-sclerotic change. The difference in appearance lies in the fact that in this group the main circulation is very efficient, and therefore the arterial obstruction must be practically complete to cause glomerular changes. The latter, therefore, occur more rapidly, as the glomerular circulation is maintained to the last possible moment by the high blood pressure. The interstitial reaction is for the same reason more intense. The grouping of the destroyed glomeruli is also due to the fact that certain groups of arteries are more affected than others. 
The main diagnostic point, therefore, as both Jores $\left(1904^{23}\right)$ and Löhlein $\left(1910^{15}\right)$ have pointed out, is the enormous thickening of the smallest vessels of the kidney with fat change. The glomerular changes are somewhat difficult to distinguish from the senile arteriosclerotic form.

The other cases in Table IV. $(\alpha)$ may now be briefly referred to :-

CAsE 34.-The kidney changes were almost exactly the same as in Case 33. As, however, the specimen has been preserved in spirit, fat staining only showed in the centre of the specimen traces of the advanced fat change of the greatly thickened small arteries. The general appearance, however, makes it extremely probable that this fat change was really present throughout. No notes were obtainable.

CASE 35. - The changes were not so advanced, but were similar in kind. The very great thickening and fat change of the smallest arteries was conspicuous.

The history is as follows: The patient, a woman æt. 47 , first came under observation in January 1897. She was then admitted to hospital for "anæmia." The urine showed albumin and pus corpuscles, but, as the patient had had gonorrhœa shortly before, this is not of great importance. The heart was normal in size and action. In February 1908 the patient was again admitted with an apoplexy causing right hemiplegia.

The blood pressure was greatly increased. The heart was enlarged and hypertrophied. The urine contained at times a trace of albumin, occasionally a cast or two was found; this, however, was not constant. The amount was somewhat diminished at the beginning of her stay in hospital. Later it was not measured. Albuminuric retinitis of slight degree was doubtfully present. She was discharged in August 1908.

She again came in in January 1909, having brought up a large amount of black blood. She had also various pains in the body and was breathless. There was no cough and no rise of temperature. The heart was very large, with forcible apex beat. The urine showed a slight amount of albumin. No casts were found. It varied in amount, but often was increased above the normal. Undoubted retinitis albuminurica was observed. CEdema was never present. Discharged 28th January 1909.

She came in again for the last time on the 1st March 1909, and died five days later. She had had another bringing up of blood on 27th February, and also melæna. She was somewhat somnolent and slightly delirions. There were signs of broncho-pneumonia. The urine was not measurable. Albumin was present. She finally developed Cheyne-Stokes breathing, and died.

Post-mortem.-Multiple areas of old hamorrhage were found in the basal ganglia of the brain. The heart was very greatly hypertrophied. The aorta was hypertrophied, with a smooth wall showing only a few small yellow flecks. Broncho-pneumonia was present. The kidney showed a fresh thrombosis of a number of the larger arteries. This is interesting, in view of the cause of death in Case 36 . The cause of the melæna was not noted in the post-mortem records.

Case 36. - Showed also similar kidney changes. The thickening of the smallest arteries was again very conspicuous.

The arterio-sclerotic change in the main kidney arteries was advanced, and had given rise to a thrombosis in the main artery of both organs. That this thrombosis was intra vitam was shown by its adherence to the artery wall and also by the condition of the kidney tissue.

In the left kidney the tissue was in an early stage of necrosis, scattered 
over with leucocytes. The right side also showed some early changes, but not so markedly.

This extremely exceptional condition was the direct cause of the death of the patient, who died with symptoms of uræmia.

The heart was greatly hypertrophied, and the ascending arch of the aorta was smooth and normal.

As the patient, a woman æt. 62 , was brought in comatose with symptoms of uræmia and died shortly after admission, a history was not obtainable. The urine, obtained on admission, showed 2 per cent. albumin, granular casts and blood, kidney epithelium and leucocytes.

Post-mortem.-The heart was very greatly hypertrophied. The mitral and aortic valves were sclerosed. Arterio-sclerosis of the coronaries was present. The brain showed marked arterio-sclerosis of the basal arteries. No hæmorrhages were found. There was some arterio-sclerotic change in the abdominal aorta. The general artery condition in this case therefore shows some senile arterio-sclerotic change; this is not surprising, as the patient was 62 years of age.

The thrombosis of the kidney arteries appeared to be dependent on the unusually great change present in them. This type of disease seems to give rise easily to thrombosis of greatly altered arteries. For thrombosis was also present in Case 35 in the smaller kidney arteries, as has already been described.

This group of cases is therefore characterised by great change in the cerebral arteries, as well as in those of the kidney.

In two, old cerebral hæmorrhages were present in the basal ganglia, and in Case 33 fresh hæmorrhages were probably the cause of death.

(b) The second group of this type is that in which this cerebral arterial change greatly outweighs the condition in the kidney. Death has occurred, as the direct result of cerebral change in the basal ganglia, taking the form of either hæmorrhage or softening.

Case 37 will here be taken as the type.

CASE 37.-The patient, a man 2 t. 34, developed symptoms, six weeks before death, which were considered to be those of dementia præcox. He had some three months previously retired from his business, and had in the meantime absorbed a large quantity of spirits. He finally died in a condition of stupor with a terminal aspiration pneumonia.

The urine was examined and found to be normal.

Post-mortem.-The heart showed a moderate hypertrophy. The aorta was normal. The brain showed a great arterio-sclerosis of the basal arteries extending into the smallest branches. There were three areas of softening present in the left nucleus lentiformis, the left claustrum, and the right pons.

A section of the area of softening in the pons is shown in Plate XXXVIII. Fig. 11. The artery supplying this area is seen to be practically occluded, and explains the reason why the softening occurred. Fat staining was not possible, as the section was made by the paraffin method, but it is probable from its appearance that this artery had fat change in its wall.

The small arteries of the pancreas also are greatly thickened, and show a most marked fatty change of their intima.

Macroscopically, the kidney appeared normal.

Microscopically, the condition is shown in Plate XXXVII. Fig. 10.

The smallest arteries are seen to be markedly thickened, with fat change, in the manner that has been already described. This change has, however, in this case not progressed so far as to cause change in the kidney substance of 
any importance; only one or two altered glomeruli with surrounding fibrous increase are to be seen in any section. Practically the whole of the kidney tissue itself remains normal. This case is therefore held to be a very early stage of the condition as regards the kidney. The briin is here the organ which has become chiefly affected. The heart hypertrophy here, though considerable, is not so great as in the group of cases already described, as the small artery change is not sufficiently advanced, and probably las not lasted long enough to cause an extreme hypertrophy. Unfortunately the blood pressure was not taken.

Of the two other cases in this group, CASE 38 had a clear history of two apoplectic attacks, the second of which proved fatil on the day of admission.

The right kidney macroscopically showed depres.ions on the surface having the appearance of infarcts, and the left showed hydronephrosis and atrophy owing to a stone inmpated in the left ureter. The hent was sreatly hypertrophied. The aorta was normal. The brain showed an old apoplectic nodule in the left putamen and a fresh hæmorrhage in the right nucleus lentiformis and caudatus.

The apparently infarcted area in the right kidney was seen to lie over an old hæmorrhage lying in the peripelvic tissue. Microscopical examination showed that this hæmorrhage was old, and that the condition above was a pressure atrophy directly due to it.

The rest of the kidney showed the change in the small arteries already described, with here and there destroyed glomernli. The kidney tissue was practically normal.

CASE 39 showed microscopically similar but more advanced changes in the kidney. The eause of death here also was hæmorrhage into the pons.

The patient, a man 2 t. 50 , had had an illness nine months before admission, said to be "kidney disease." For two months before he had been breathless and had had palpitation of the heart. He was brought in semi-comatose with symptoms of left cerebral himorrhage. The heart was greatly enlarged and hypertrophied. No œdema was present. Retinitis albuminurica was not found. He recovered considerably for a time, but after having been in a month he had another attack with mental confusion and Cheyne-Stokes breathing. He got slightly better from this, but a third and final attack caused death after he had been in hospital six weeks.

His blood pressure was always high, varying between 260 and 156 . The urine showed, on admission, some casts, leucocytes, and epithelium, and $2 \frac{1}{2}$ per mille albumin. A few days later the albumin dropped to $\frac{1}{2}$ per mille, and the amount increased to between 2500 and 3000 c.c.

This latter condition continued to the end.

Post-mortem. - The heart was greatly hypertrophied. The aorta was smooth but for a few small yellow flecks; its wall was hypertrophied. The kidney was somewhat decreased in size, and its cortex was diminished.

The brain showed a fresh hæmorrhage into the pons lying at the base of the fourth ventricle and invading this cavity. Areas of old hæmorrhage were present in other parts of the basal ganglia. Great arterio-sclerosis of the cerebral vessels was present. Hæmorrhages were also present in the stomach, intestine, and mucous membrane of the bladder.

This group $(b)$ is therefore held to be an early stage of group $(a)$. It shows similar arterial changes in the kidney and brain, with but little change in the kidney substance itself, as the arterial changes are not yet sufficiently advanced in this organ; the cerebral changes have caused death before this could take place.

(c) Two cases yet remain to be described, in which the general 
vascular condition is similar, but the kidney changes are of a different. and remarkable type.

The greater number of glomeruli are unaltered, others show thickened capsules and are shrunken, while one or two are totally destroyed in the usual manner. Here and there, however, in each section a glomerulus is seen (Plate XXXVIII. Fig. 12), with one or two capillaries extraordinarily conspicuous. They are enormously enlarged, and their walls are very thick and homogeneous; they stain bright pink with eosin and yellow-brown with van Gieson's stain; irregular nuclear remains are also seen in them. The lumen often contains a considerable amount of blood. The whole glomerulus is also full of blood, but other capillaries remain otherwise quite unchanged. These altered capillaries also stain irregularly with fat stain. Other glomeruli show practically all the capillaries altered in the same manner but to a less degree. The capsular space in the altered glomeruli often contains blood.

It is noteworthy that in these partially altered glomeruli the arteria afferens also partakes in the very great homogeneous swelling. It may again be emphasised that these glomeruli are very few.

The tubules are considerably affected, showing changes in their lining cells and also dilatation with casts and débris in the lumen. Some tubules also contain blood.

This description is from Case 40 , but holds also for Case 41 , though here the extreme swelling of the capillaries is not found.

The histories may now be shortly related.

CASE 40.-Patient, a woman æt. 43. She was on September 13, 1908, found senseless on the floor. On admission was comatose. No cedema was present. Urine was dark (? blood), contained 3 per mille albumin and sugar. Amount, 1200 c.c. Later the urine increased to 2200 c.c. Blood pressure, 200. The heart was enlarged, with a systolic murmur at apex. Retinitis albuminurica was present.

The mental condition improved a little, but on 25th October the urine diminished in amount to 1000 c.c., albumin 2 per mille, and the patient again was mentally affected. On October 29 pericarditis was observed. On November 2 she became comatose, and on November 4 died in coma.

Post-mortem.-General arterio-sclerosis of the small arteries throughout the body was found. The aorta showed only slight changes. The heart showed great hypertrophy, especially of the left ventricle, also fresh pericarditis. The heart muscle showed necrosis. There was arterio-sclerosis of the coronaries. In the brain were a fresh hæmorrhage into the pons, and old areas of hæmorrhage in left centrum ovale and nucleus lentiformis. The cerebral arteries were much sclerosed.

The kidney was pale, with irregular red points over it, and was slightly and very coarsely granular. 'Traces of hæmorrhage into the pelvis were observed. The cause of death was pontine hæmorrhage.

The second case (41), a man æt. 33, was admitted on October 8, 1910, suffering from heart palpitation and cough with blood-stained sputum accompanied by a feeling of suffocation.

The pulse was on admission irregular and rapid, rate 120. The heart was enlarged, no murmurs present. 
The urine showed a trace of albumin,-amount 1800 c.c. A few hyaline and granular casts, lencocytes, and epithelial cells were observed.

From this time onwards urine increased in quantity up to 3500 c.c. The blood pressure was found to be 250 . The temperature was never raised.

On October 25 the albumin was first measurable, 0.6 per mille, the urine amount now falling. On November 3, signs of an embolus in the left cerebral cortex. Later breathless, then becoming delirious, with, on November 5, retention of urine. A catheter specimen showed much albumin and a few casts. On November 17 retinitis albuminurica was observed. Urine only obtained by catheter.

There was never odema. Finally exitus in delirium.

Post-mortem.-The heart was very greatly enlarged. Fresh pericarditis was present. General congestion of organs. Brain.-Old apoplectic nodule in the left nucleus lentiformis. Fresh hæmorrhage into left pons, - the cause of death.

These cases appear to be cases of the type at present under discussion, with an additional terminal very acute and very localised kidney change. It is also remarkable that both had an acute pericarditis. Whether the glomerular appearances can be explained on the lines of an acute bacterial embolic affection of certain capillaries by the organism that at the same time caused the pericarditis, there is not enough evidence to say. It is merely offered as a possible explanation.

This group of cases has been dwelt upon at length, as it is considered that the recognition of this primary vascular affection of the small arteries and its secondary kidney and brain manifestation is extremely important from both the clinical and pathological point of view. It may be noted that the high blood pressures recorded are probably approximately near the truth, as the arteries of the limbs are in some cases, at any rate, little affected by any arterio-sclerotic change. The splanchnic area also seems frequently to escape. The alteration of the cerebral vessels is extremely conspicuous throughout the series.

In only one case was there no post-mortem evidence of either old or fresh hemorrhage in the basal parts of the brain. In many this was the direct cause of death. The kidney changes here, on the whole, are comparatively unimportant from the point of view of danger to life. The one case (36) in which death was directly due to the kidneys was due to a thrombosis of both the kidney arteries, which must be an extremely rare occurrence. The urinary changes are usually slight, till terminal changes and subsequent kidney disorganisation set in, owing to lowering of the blood pressure and congestion of the organ. The tendency to hæmorrhage in other parts of the body as well as in the brain is a striking feature throughout the series.

The presence of albuminuric retinitis in many cases of this group is also of interest. It is probable that this, as one would expect, is really much more a sign of cerebral arterial disease than of kidney change. The investigation of the cerebral arteries in secondary contracted kidney should therefore prove of interest. 
The view is maintained, therefore, that the "genuine Schrumpfniere" is always secondary to an arterio-sclerosis of the smallest arteries of the kidney, which is merely part of a general change of the same type in the brain and other parts of the body. The condition is also characterised, in direct contrast to the senile arterio-sclerotic change, by great heart hypertrophy with accompanying hypertrophy of the aortic wall, in which true arterio-sclerotic changes are practically absent. The original cause of the condition does not come within the scope of this paper. The question is not to be settled at present. In order to investigate it, it is necessary to have an exact examination of the small arteries of all the organs of the body and also of the extremities, so as to decide the incidence of the change in these structures. If the disease affects all the arteries it must be due to a special disposition or a continual intoxication, with, possibly in addition, hyperirritability. But if only a few organs (or only one) are affected, then the possibility arises that it is a question of excessive over-work and functional damage of the particular organs or organ affected.

\section{Summary.}

1. The changes in the glomeruli and arteries afford a means of differentiating the forms of kidney disease under discussion in agreement with clinical findings.

2. These changes can be divided into two groups-(1) the inflammatory and its secondary changes, (2) the vascular.

3. The lasting inflammatory changes, with the exception of that accompanying ulcerative endocarditis, are always due to a true glomerulo-tubular nephritis. This group can again be divided intodifferent stages-(a) the acute, commonly known as acute parenchymatous nephritis; (b) the subacute, or reparative stage, commonly called large white kidney; and $(c)$ the sclerotic, commonly designated secondary contracted kidney or, most inaccurately, small white kidney. This form of disease frequently leads to death from uræmia at a comparatively early age.

4. The ulcerative endocarditis type, here called embolic focal nephritis, can be separated from the group just summarised by its typical glomerular changes. Death here occurs from the condition of the heart.

5. The vascular group can be subdivided into two groups(a) the senile arterio-sclerotic, and (b) the "genuine Schrumpfniere" or "primary contracted kidney" type, which is due to primary arteriosclerosis of the small arteries.

6. The primary change in the senile arterio-sclerotic group is initially localised in the aorta and large vessels. It then spreads into the arterial branches of the kidney. This causes disuse atrophy, and degeneration of glomeruli and their tubules owing to the direct 


\begin{tabular}{|c|c|c|c|c|c|}
\hline 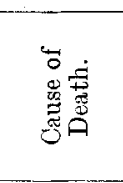 & 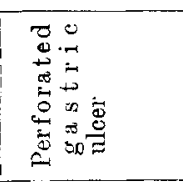 & $\begin{array}{l}z \\
0 \\
0 \\
0 \\
=0 \\
=0 \\
0 \\
0 \\
0\end{array}$ & 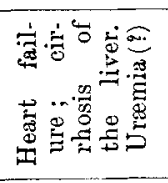 & 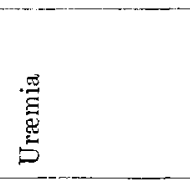 & $\dot{\grave{Q}}$ \\
\hline 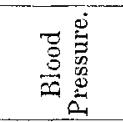 & 1 & 1 & 1 & $\stackrel{\stackrel{\circ}{\circ}}{\circ}$ & 高 \\
\hline 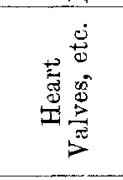 & 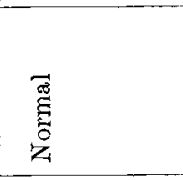 & 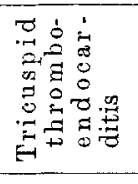 & 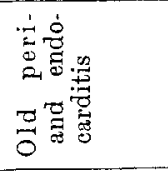 & 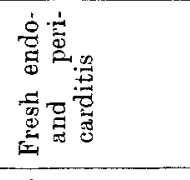 & 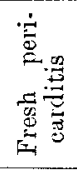 \\
\hline 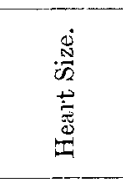 & 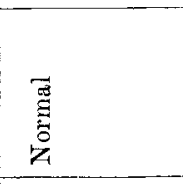 & 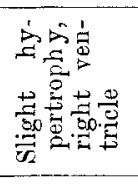 & 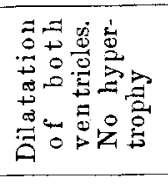 & 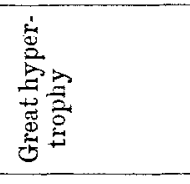 & 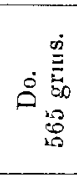 \\
\hline 要 & $\begin{array}{l}\text { 范 } \\
\text { 总 }\end{array}$ & 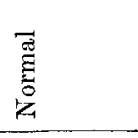 & $\dot{\AA}$ & $\begin{array}{l}\text { 范 } \\
\text { 总 } \\
\end{array}$ & $\dot{\grave{A}}$ \\
\hline 學密 & 1 & 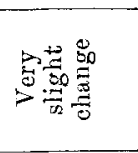 & 1 & 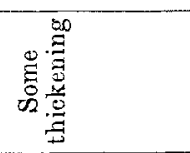 & $\dot{\leftrightarrow}$ \\
\hline 菨惫 & 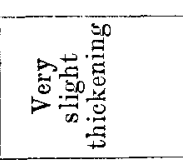 & 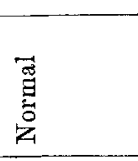 & 1 & 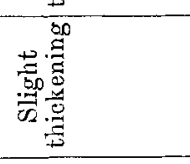 & 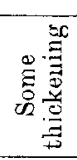 \\
\hline 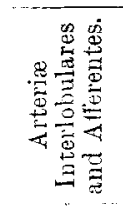 & 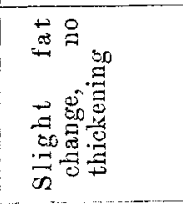 & 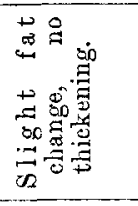 & 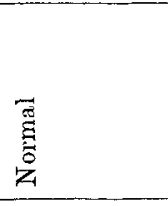 & 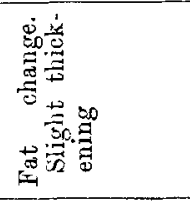 & $\dot{\leftrightarrow}$ \\
\hline 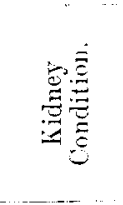 & 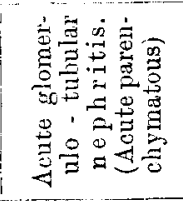 & 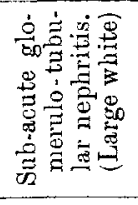 & 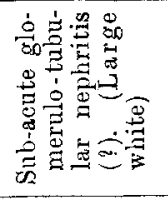 & 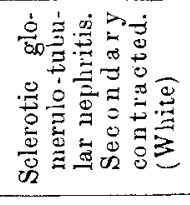 & 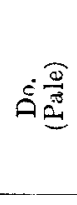 \\
\hline 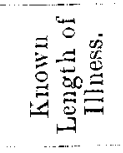 & 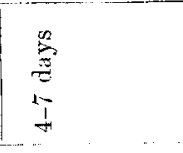 & 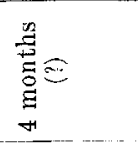 & 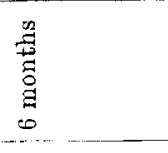 & 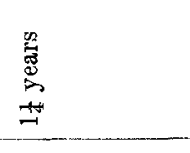 & 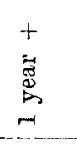 \\
\hline$\stackrel{\dot{8}}{\dot{8}}$ & \% & $\stackrel{\leftrightarrow}{\circ}$ & 总 & $\stackrel{\circ}{\circ}$ & $\vec{N}$ \\
\hline 总: & $\hat{\ddot{\theta}}$ & 总 & $\stackrel{\mathscr{N}}{\stackrel{g}{9}}$ & 足옳 & $\approx \bar{s}$ \\
\hline 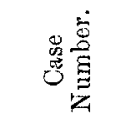 & $\overrightarrow{\text { Eे }}$ & $\frac{i}{a}$ & $\dot{\infty}$ & $\stackrel{+}{\stackrel{\theta}{S}}$ & 20 \\
\hline
\end{tabular}




\begin{tabular}{|c|c|c|c|c|c|c|}
\hline$\dot{\rho}$ & $\dot{\grave{\Omega}}$ & $\dot{\leftrightarrow}$ & 1 & 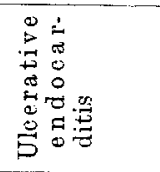 & $\dot{\circ}$ & $\dot{\ominus}$ \\
\hline 육 & $\begin{array}{l}\overrightarrow{50} \\
\text { 它 }\end{array}$ & 1 & I & 1 & 1 & $i$ \\
\hline$\dot{\leftrightarrow}$ & 票 & $\dot{\circ}$ & $\dot{\dot{\theta}}$ & 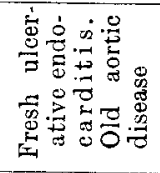 & 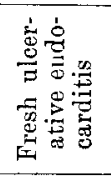 & 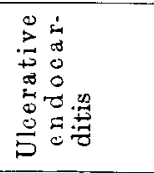 \\
\hline 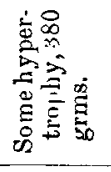 & 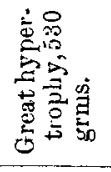 & 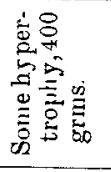 & 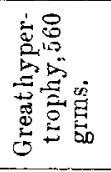 & 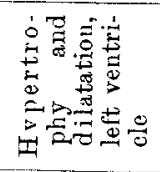 & 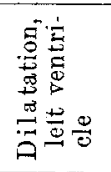 & 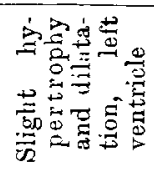 \\
\hline 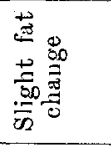 & 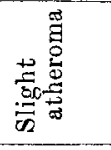 & 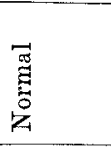 & 1 & 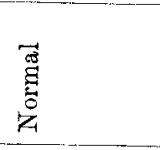 & 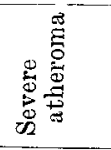 & 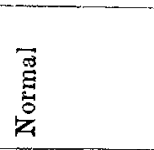 \\
\hline$\dot{\leftrightarrow}$ & 1 & 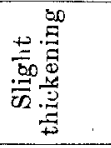 & 1 & 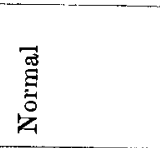 & 1 & $\begin{array}{l}\vec{\Xi} \\
\stackrel{\Xi}{\Xi} \\
\bar{z}\end{array}$ \\
\hline$\dot{\AA}$ & 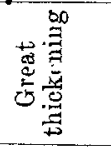 & 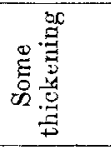 & 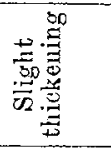 & 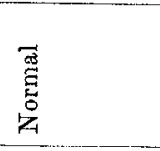 & 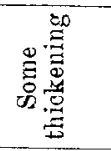 & 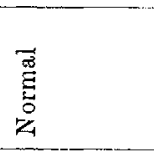 \\
\hline 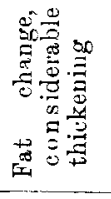 & $\dot{\mathscr{\sigma}}$ & 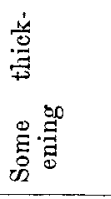 & 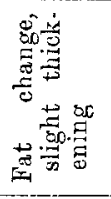 & $\begin{array}{l}\text { हु } \\
\text { है } \\
\text { ż }\end{array}$ & 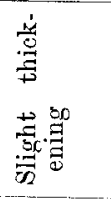 & 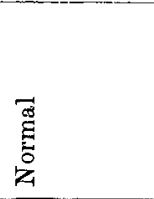 \\
\hline$\stackrel{\stackrel{0}{0}}{\underline{a}}$ & 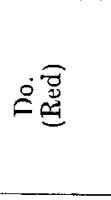 & 离 & 离 & 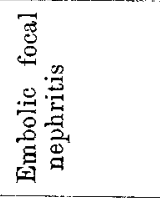 & $\dot{\circ}$ & $\dot{8}$ \\
\hline 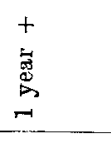 & 1 & 1 & 1 & 1 & 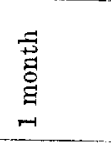 & 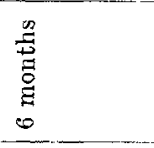 \\
\hline ㅇํ & $\mathscr{D}$ & $\overrightarrow{~ ल े ~}$ & N & 1 & $R$ & $\stackrel{2}{\rightarrow}$ \\
\hline 혀 & $\ddot{\theta}$ & $\stackrel{\sigma_{\mathfrak{\sigma}}}{\vec{\sigma}}$ & 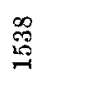 & $\stackrel{\stackrel{N}{\circ}}{\circ}$ & సั心 & 象票 \\
\hline$\dot{0}$ & $N$ & $\infty$ & $\dot{0}$ & $\stackrel{\dot{0}}{8}$ & $\dot{\Rightarrow}$ & $\underset{\sim}{\stackrel{\text { I }}{ }}$ \\
\hline
\end{tabular}




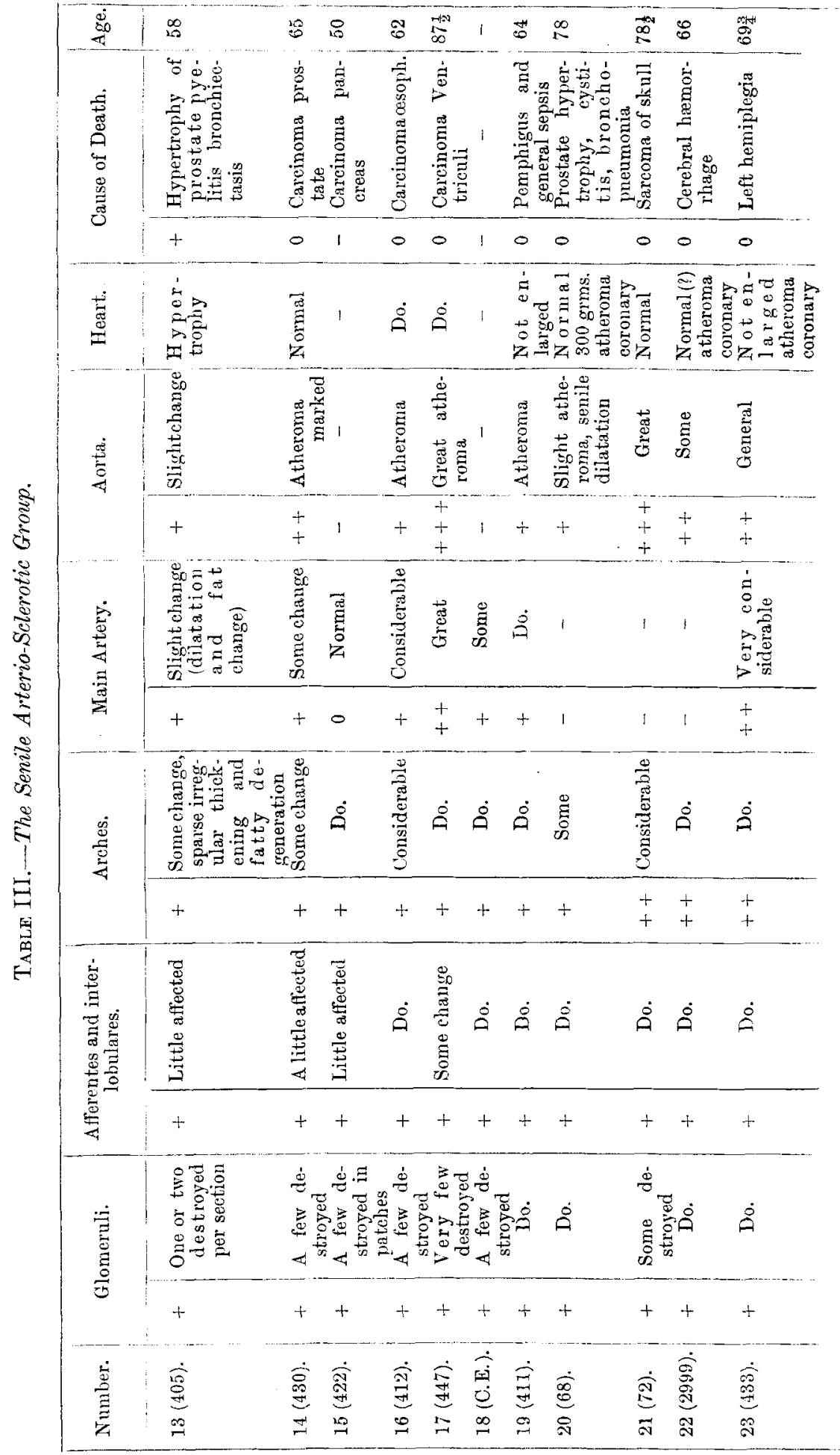




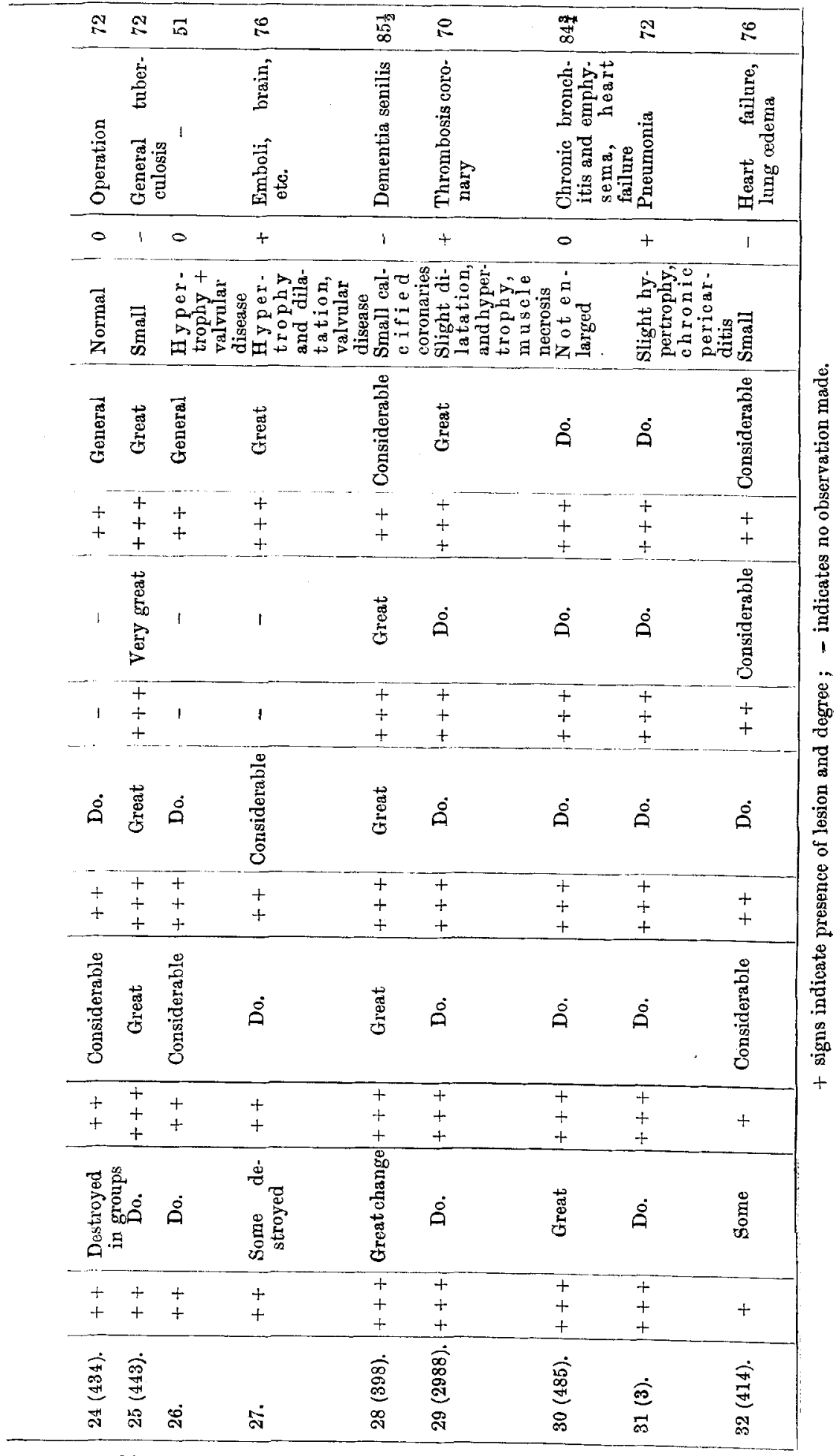




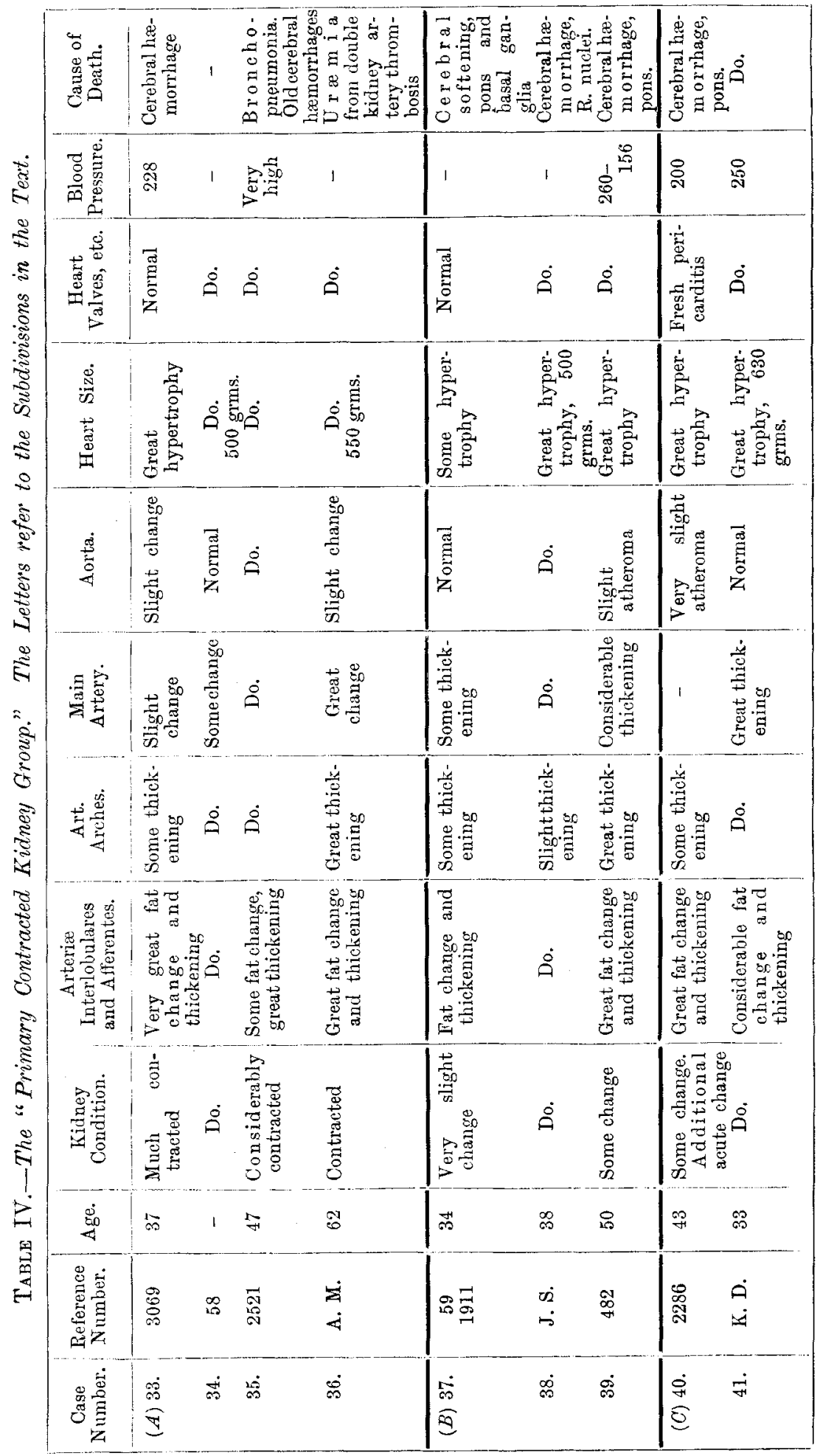


involvement of the interlobulares and afferentes. Clinically this group is of little significance, though it often gives rise to a high degree of kidney contraction. Cases of senile contracted kidney also belong to this group. There is no heart hypertrophy. The cause of death is intercurrent disease; the kidney change is only marked in old people.

7. The "genuine Schrumpfniere" type is a part only of a general pathological complex consisting of hypertrophic changes in the heart and aorta, and vascular changes in the kidney and other organs,- in particular the brain. These are directly dependent on a severe primary arterio-sclerosis of the small arteries and arterioles. Death in this group is due, usually, to cerebral hæmorrbage and usually occurs in the middle period of life.

In conclusion, I must express my gratitude to Professor de la Camp, Professor von Gierke, and others for the facilities they have afforded me of examining the clinical notes of the various cases; and again to Professor Aschoff for the advice and help which he has given me throughout the investigation.

It is hoped that this investigation may be of some slight assistance in reconciling some of the differences between the clinical and morbid changes in kidney disease.

\section{REFERENCES.}

1. Löнlein . . . . . "Ueber die enziindlichen Veränderungen der Glomeruli der menschlichen Nieren," Arb. a. d. Path. Inst., Leipzig, 1906, Heft 4.

2. Heinecre . . . . "Die Veränderungen der menschlichen Niere nach Sublimat-Vergiftung mit besonderer Beruicksichtung der Regeneration des Epithels," Beitr. z. path. Anat. u. z. allg. Path., Jena, 1909, Bd. xlv. S. 197.

3. Councilman . . . . Med. and Surg. Reports, Boston City Hospital, 1897, p. 174.

4. Chapman . . . . Journ. Path. and Bacteriol., Cambridge, 1906, vol. xi. p. 276.

5. Reichel . . . . . Ztschr. f. Heilk., Berlin, 1905, Bd. xxvi. S. 72.

6. Sohotrmǘller . . . München. med. Wchnschr., 1910, S. 617.

7. Libman and Cetider - Am. Journ. Med. Sc., Phila.,1910, vol. cxl. p. 516.

8. Herringham and Trans. Path. Soc. London, 1904, vol. lv. p. Thursfield 283.

9. AschоғF . . . . "Pathologische Anatomie," Jena, 1909, Bd. ii. S. 489 .

10. Haltenberger . . . Arch. f. klin. Med., Berlin, 1906, Bd. Ixxxvii. S. 62.

11. Dixoy Maxn. . . "On Granular Kidney following Scarlatinal Nephritis," Lancet, London, 1895, vol. ii. p. 670.

12. AschofF . . . . "Ueber Atherosklerose und andere Sklerosen des Gefässsystems," Beihefte zu Wien. Klinik, 1908, Jahrg. iv. S. 1. 
13. Honder . . . . Quarterly Journal of Medicine, 1909, vol. ii. p. 289.

14. Lenhartz. . . . . München. med. Wchnschr., 1901, Bd. xliii. S. 1123.

15. Löhlein . . . . . Ergeb. d. Inn. Med. u. Kinderh., 1910, Bd. v. S. 411.

16. Herxheimkr. . . "Ueber die sogenannte hyaline Degeneration der Glomeruli der Niere," Beitr. z. path. Anat. u. z. allg. Path., Jena, 1909, Bd. xlv. S. 253.

17. FAHR . . . . . "Ueber chronische Nephritis und ihre Beziehung zur Arteriosklerose," Virchow's Archiv, 1909 , Bd. excv. S. 228.

18. Starling . . . . . Joum. Physiol., London, 1899, vol. xxv. p. 317.

19. Aschoff and Gaylond. "Lehrbuch," 1902.

20. Ruckert . . . . . Orth's Festschrift, Berlin, 1903.

21. Gull and Sution . . Brit. Med. Journ., London, 1872, vol. i. p. 680 ; Med.-Chir. Trans., London, 1872, vol. lv. p. 273.

22. Johnson . . . . . Brit. Med. Journ., London, 1872, vol. i. p. 256.

23. Jores And Prim. . " "Ueber die Arterio-sclerose der kleinen OrganArterien und ihre Beziehungen zur Ñephritis," Virchow's Archiv, 1904, Bd. clxxviii. S. 367.

\section{DESCRIPTION OF PLATES XXXIII.-XXXVIII.}

Plate XXXIII.

FIG. 1.-Glomerulo-tubular nephritis; acute stage, of probably four days' duration. Case 1.-The glomerulus $\mathrm{G}$ is greatly swollen, its capillary structure is obscured, and its nuclei are irregular and often fragmentary. Some polymorpho-nuclear leucocytes (p.l.) are present in places, while other eapillaries (d.c.) are distended with blood. The glomerulus shows a tendency to project hernia.wise $(h)$ down the first part of the tubule $(t$.$) Bowman's$ capsule (B.c.) is stretched tightly over the glomerulus, but is not otherwise altered. The lining cells of the tubules are in various stages of swelling, and the tubules contain various contents. There is also some interstitial edema separating the tubules from one another.

FIG. 2.-Glomerulo-tubular nephritis ; reparativestage. (Large white kidney.) Case 2.The glomernlus $G$ is large, irregular in shape, and its structure is confused. It contains little blood, and has an excess of irregular nuclei in places. At one point $(a)$ it is adherent to the thickened Bowman's capsule (B.c.). At $d$ is a group of desquamated cells. There is some cellular increase in the region of the hilum $(h)$, and the general interstitial tissue is greatly increased. The tubules are lined by irregular degenerating cells, and contain débris in their lumen.

\section{Plate XXXIV.}

FIG. 3.-Glomerulo-tubular' nephritis; sclerotic stage. (Secondary contrasted kidney.) Case 5. - The glomerulus $\mathrm{G}$ has to a great extent recovered, and shows mostly regular oval nnclei. One half is, however, adherent to, and blended with, the capsule. The other half is free and is becoming reclothed with new epithelium (e), which is also clothing the capsule wall and a fibrons strand running across the capsule space. The tubules are either atrophic $(\alpha t$.) or much dilated and lined by fairly regular flat epithelium $(d t$. $)$ There is great increase of the interstitial fibrous tissue. 
Fig. 4.-Glomerulo-tubular nephritis; sclerotic stage. (Secondary contracted kidney.) Case 5.-General view under the low power. Most glomeruli, as at $d$, are degenerated and blended with the surrounding tissue. At $\alpha$, however, is a hyaline glomerulus with two small remains of capsule space clothed with new epithelium; and at $b$ a glomerulus better preserved with many layers of new epithelium in the capsule space. Groups of dilated tubules $(t$. $)$ are seen scattered amongst the greatly increased fibrous tissue; the remains of degenerated tubules, however, outnumber these.

\section{Plate XXXV.}

Fig. 5.-Embolic focal nephritis, from a case of ulcerative endocarditis. Case 11.-Hæmatoxylin and van Gieson's stain. The glomerulus is only partly affected, the greater part showing normal capillaries $(n)$ with normal capsule space and normal Bowman's capsule (B.c.). Some of the capillaries $(a)$, however, show great changes; their structure is confused, and they are blended into a mass with the capsule. There is an increase of cells with large nuclei in this mass, probably epithelial in nature, and also a great increase of leucocytes (l.c.) with some round cells. This infiltration involves also the neighbouring tissues. The tubules are variably affected, some being lined with regular cells $(t)$, others with irregular swollen cells $(t$.$) .$

Fig. 6.-Arterio-sclerotic contracted kidney of advanced type, from Case 30. Stained by hæmatoxylin and van Gieson's stain. There is a general irregular fibrous increase. The greatly thickened interlobularis $(i)$ is very irregular in contour, and its lumen is much diminished. The orange-red coloured portion is all thickened intima; the thin muscle layer outside this is not conspicnous. Glomeruli are seen in various stages, some slightly shrunken (s), others much shrunken $(a)$ with thick capsule, and others completely destroyed $(b)$ with marked differentiation of the brown remains of the glomerulus and the deep-red staining degenerate capsule. Many normal glomeruli were to be seen in other parts of the section, this particular field being taken from one of the most affected areas.

\section{Plate XXXVI,}

Fig. 7.-Arterio-sclerotic contracted kidney. Case 23.-Showing a shrunken glomerulus and its thickened capsule (B.c.). The arteria afferens (A.a.), though its wall is irregularly thickened, is not occluded. The degenerated tubules (d.t.) belong to this shrunken glomerulus. The fibrous patch is surrounded by normal tubules, with the normal amount of interstitial tissue between them. The fibrous tissue is not rich in nuclei, and is cedematous.

FIG. 8. The same glomerulus as Fig. 7, at the point where its tubule comes off. The commencement of the tubule (c.t.) is very small, and lined with atrophied cells. Its further convolutions have been traced in the neighbouring sections, and all the atrophied tubules (a.t.) belong to this glomerulo-tubular system. There is commencing round-celled infiltration (r.c.) in the region of these atrophied tubules. Otherwise the connective tissue is not rich in nuclei. A dilated capillary, filled with blood, is seen at d.c.

\section{Plate XXXVII.}

FIG. 9.-Primary contracted kidney, "Genuine Schrumpfniere." Case 33.-Hæmatoxylin and sudan III. The smaller arteries of the kidney are enormously thickened, both the interlobulares $(A . i$.) and the afferentes $(A . a$.$) . They have practically$ no lumen left. Their wall shows a variable but considerable fat content. A contracted shrunken glomerulus with thickened capsule in seen (c.g.). Also a totally destroyed glomerulus (d.g.). A group of atrophied tubules (a.t.) lie in increased fibrous tissue, while groups of normal tubules (n.t.) 
are also seen with no connective-tissue increase. In other less affected parts of the section many large normal glomeruli are seen similar to that seen in Fig. 10.

Fic. 10.-Antecedent stage of primary contracted kidncy (Fig. 9). Case 37.-Hæmatoxylin and sudan III. There is here no alteration of the kidney substance; a normal glomerulus $(n . g$.$) is seen lying among normal tubules. The arteries, however,$ both interlobulares (A.i.) and afferentes (A.a.), have greatly thickened walls, showing a considerable amount of fat. There is still a permeable lumen to them, though it is often very small. Around these lie congested capillaries (d.c.). There is no interstitial increase.

\section{Plate XXXViII.}

FIG. 11.-Area of softening in the pons, with its supplying artery. Case 37.-Paraffin, hæmatoxylin, and eosin. The artery wall is enormously thickened, very nearly occluding the lumen. It is probable that this occlusion was even more marked before the fat was dissolved out of the wall by the method of preparation.

FI(x. 12.-Glomerulus from Case 40.-Hæmatoxylin and van Gieson's stain. There is extreme swelling of certain capillaries (s.c.) in the glomerulus; these have a yellow-brown colour. The arteria afferens $(A . a$.$) at its entrance is also$ affected in a similar way. There is much blood in these capillaries, and also a considerable amount in the sound capillaries (n.c.). Bowman's capsule is distended, but otherwise unaltered. Blood was seen in the capsule space of this same glomerulus in other sections. 


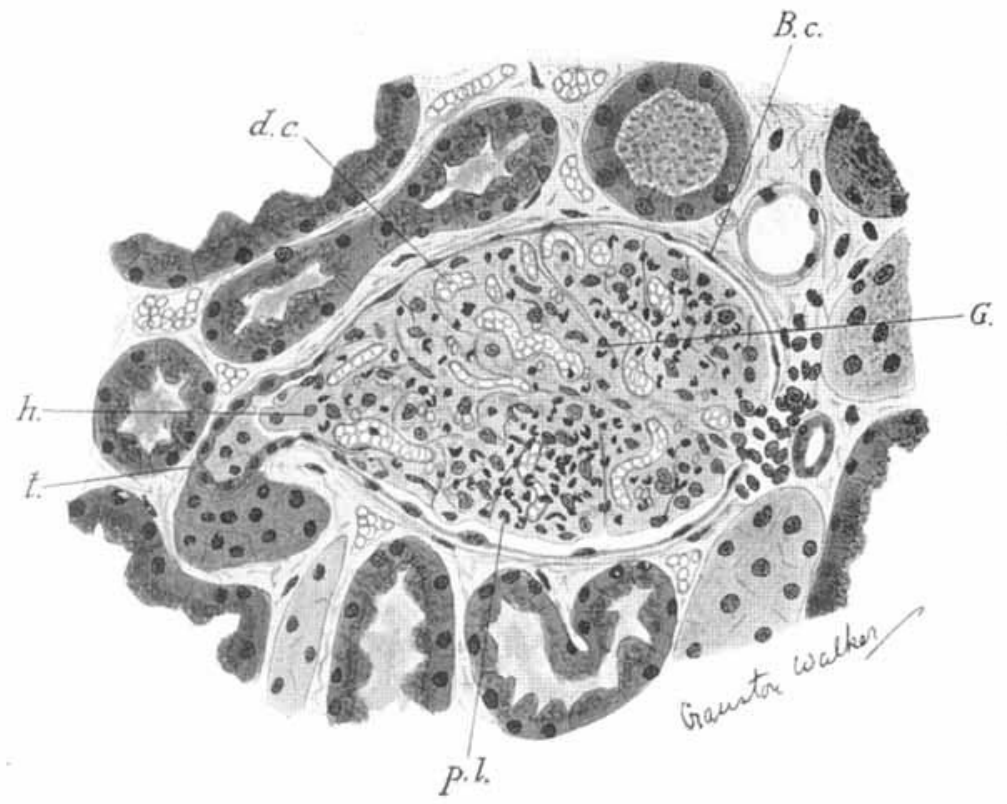

Fig. 1.

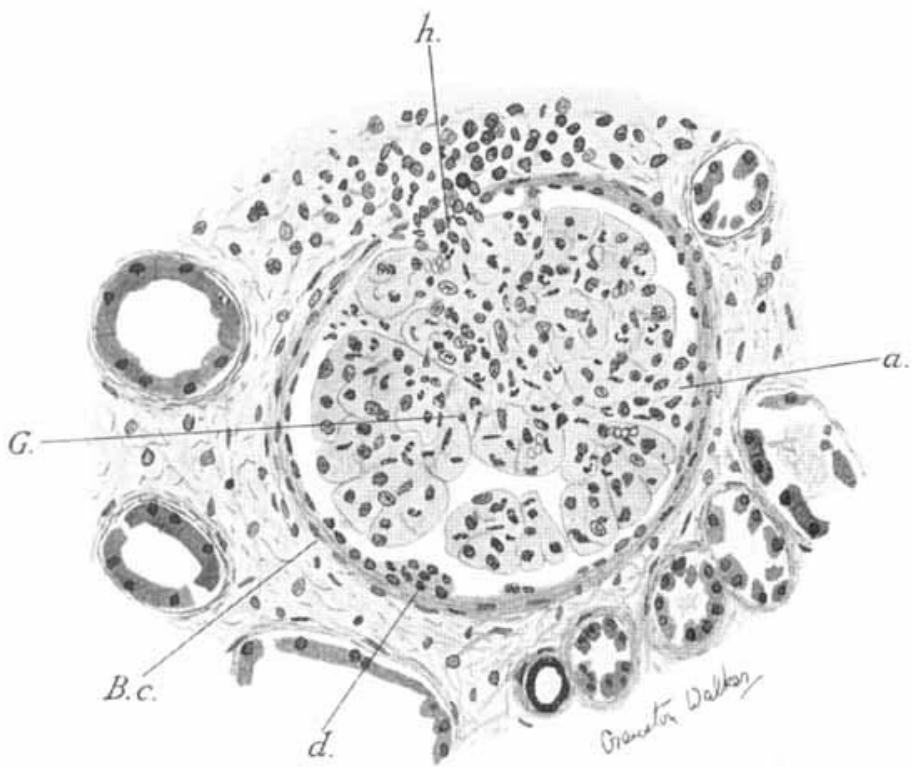

FIG, 2, 


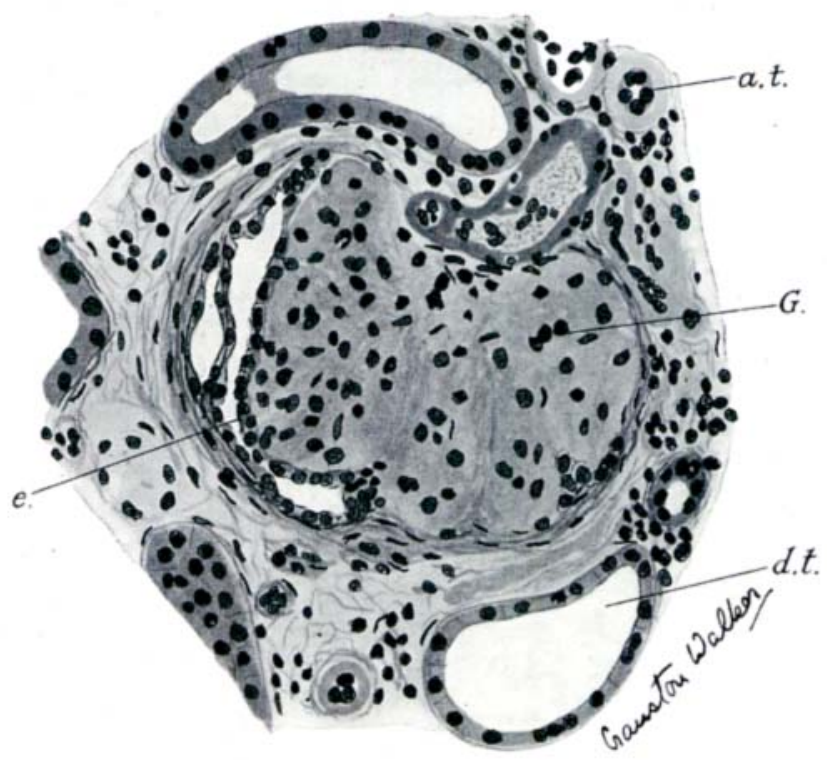

FIG. 3.

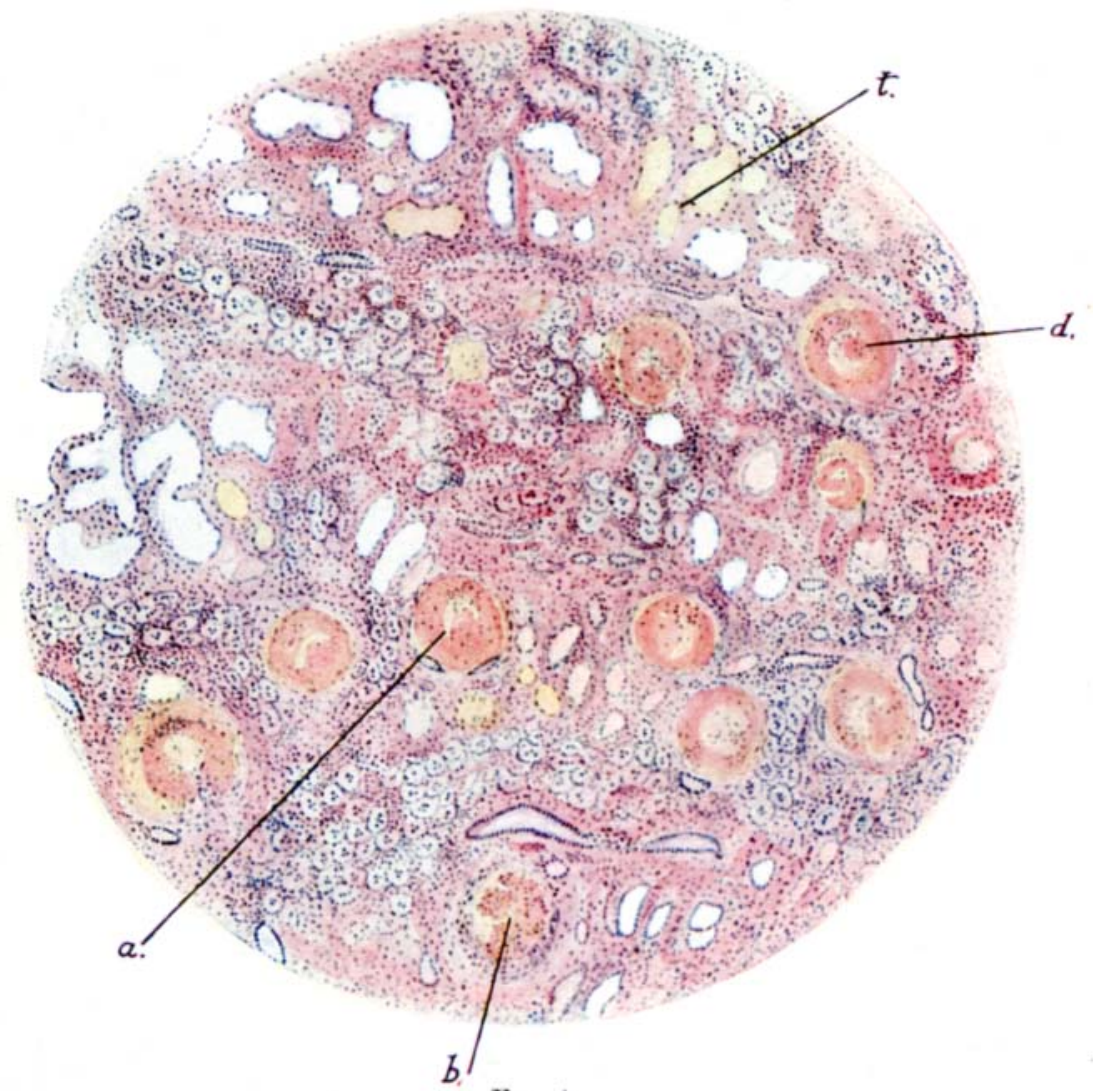

Fig. 4 . 


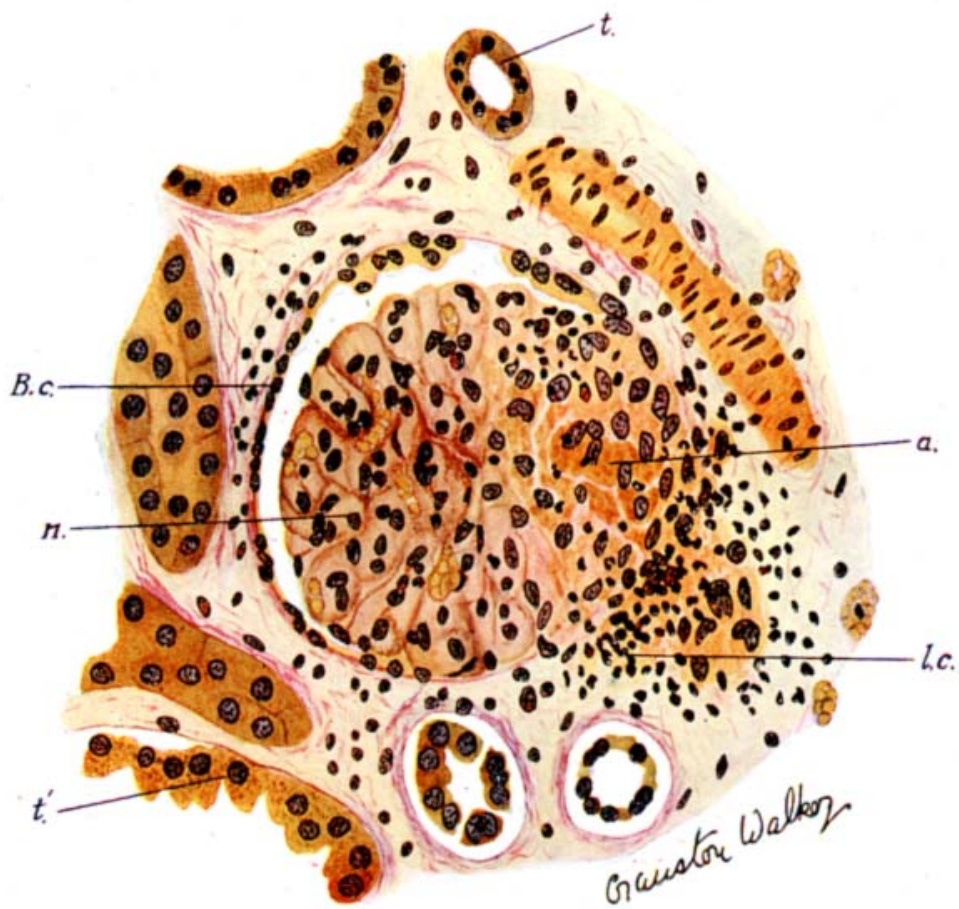

Fig. 5.

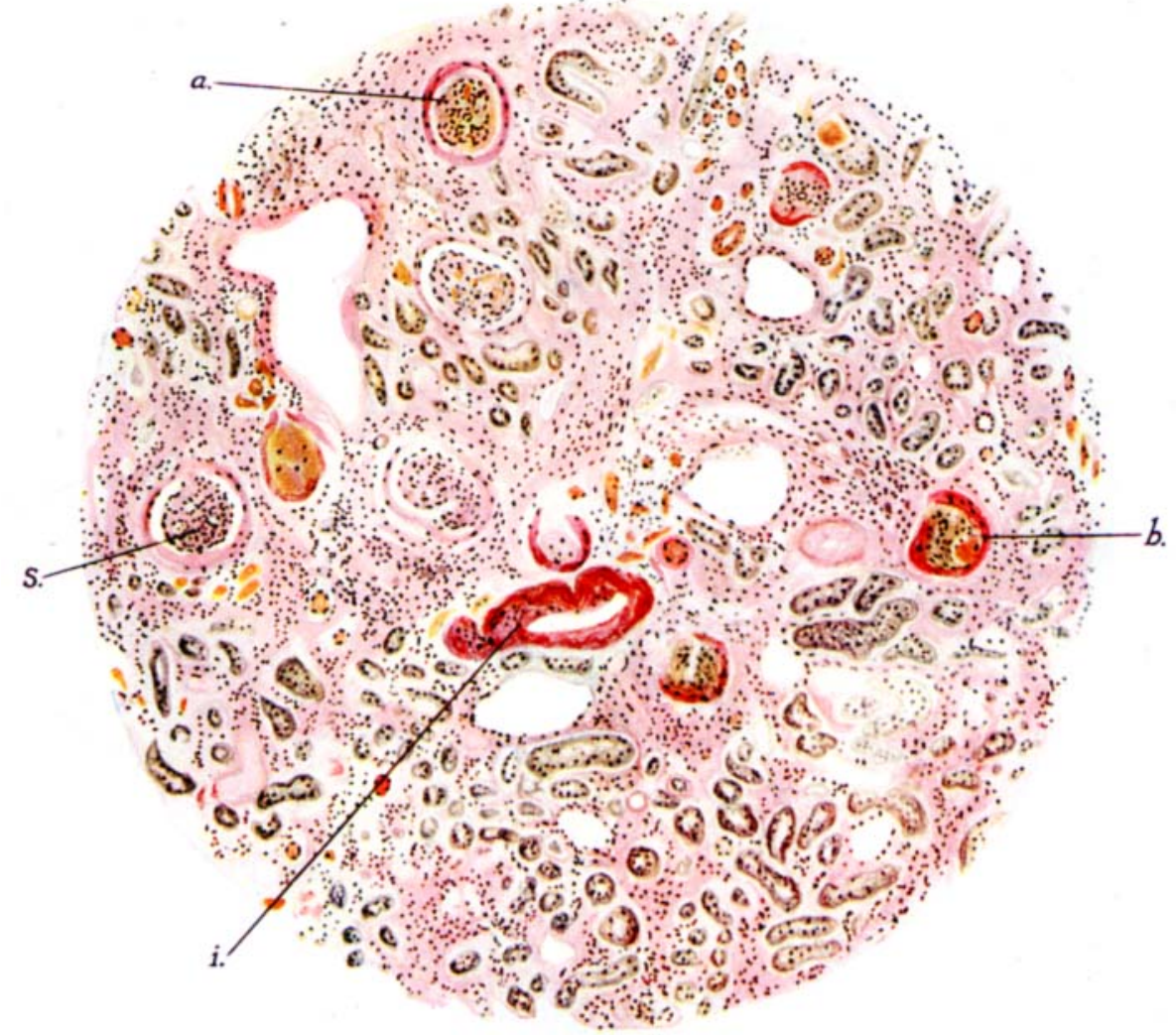

FIG. 6. 


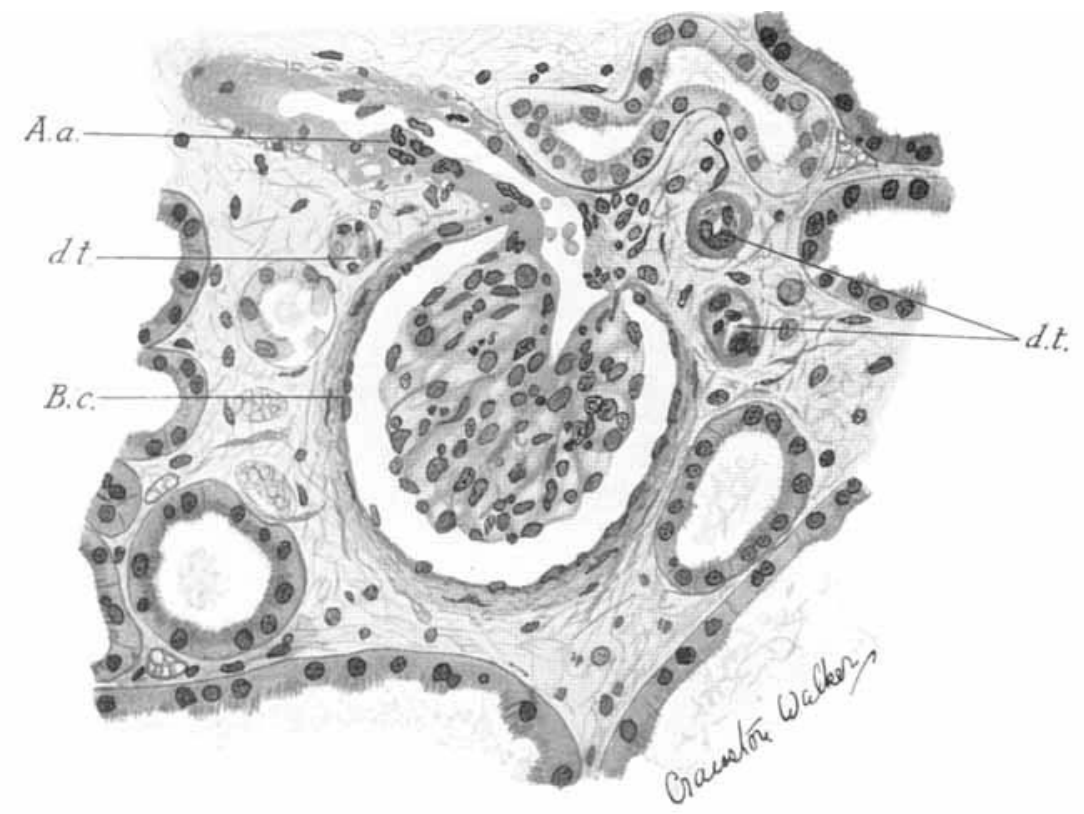

Fig. 7.

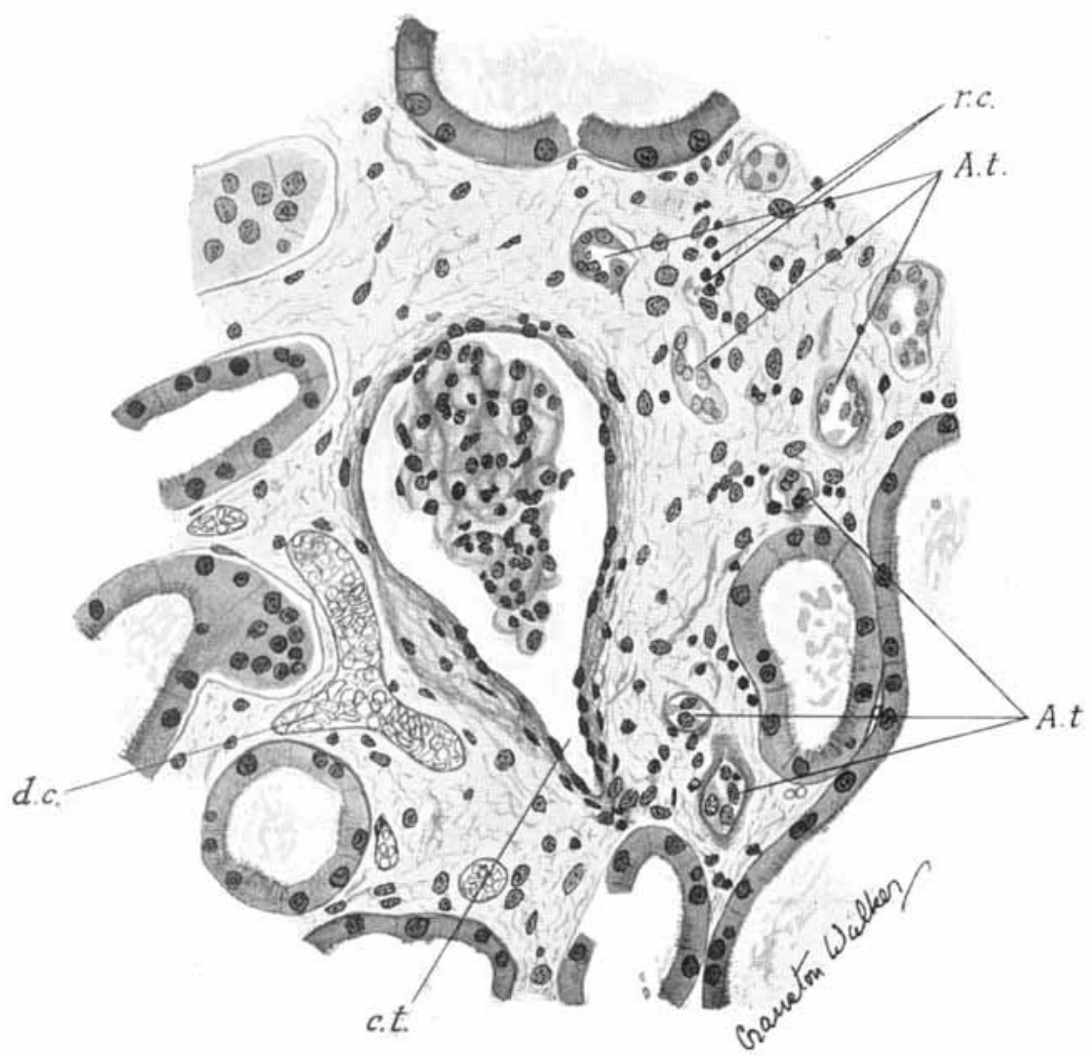

Fra. 8. 


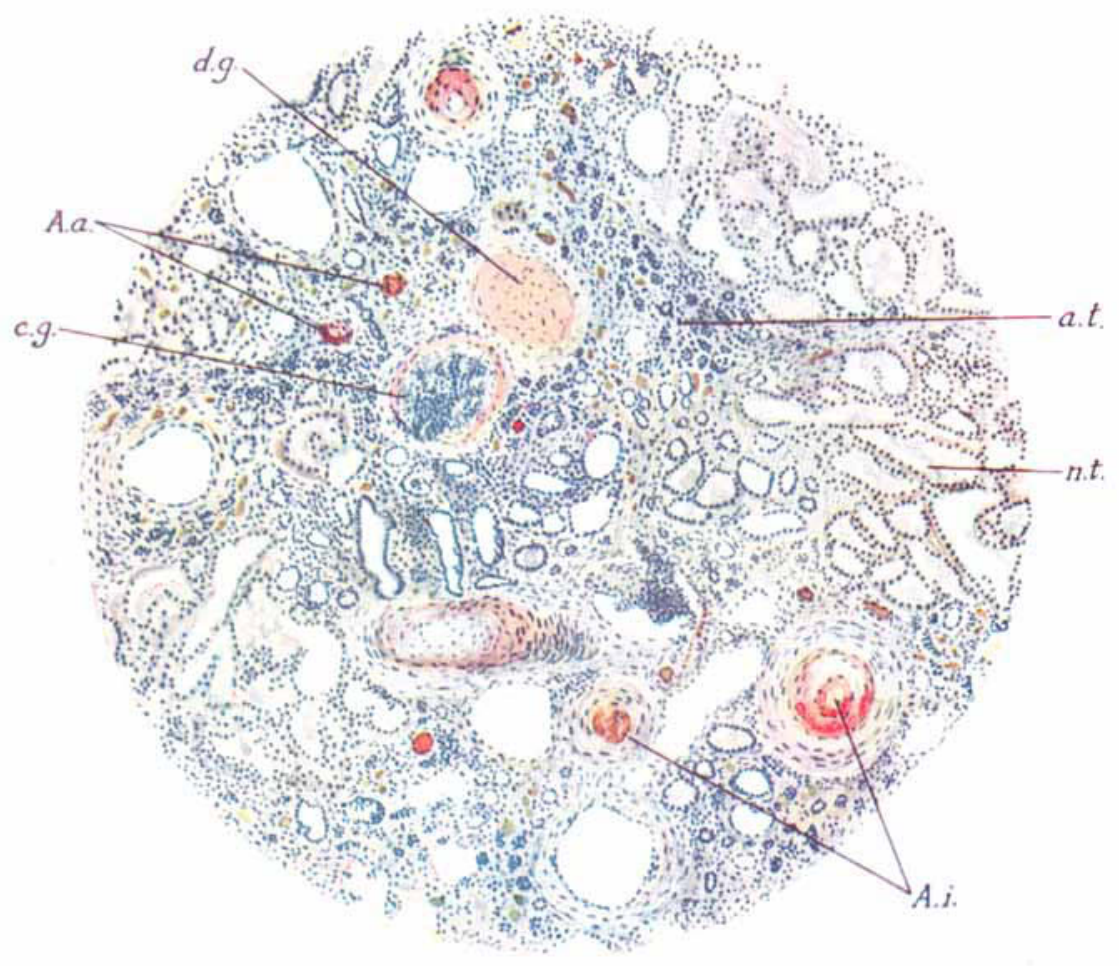

Fig. 9.

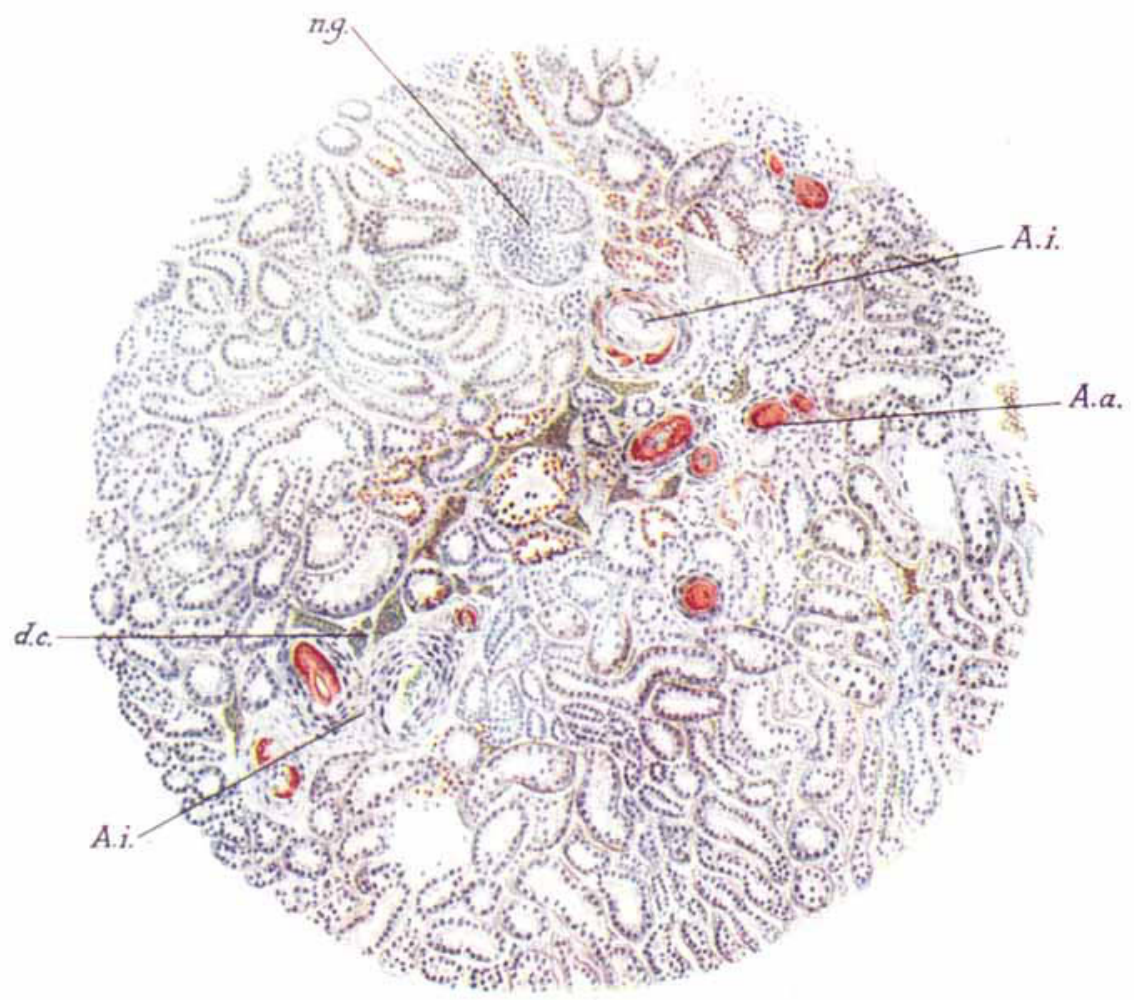

Fig. 10. 


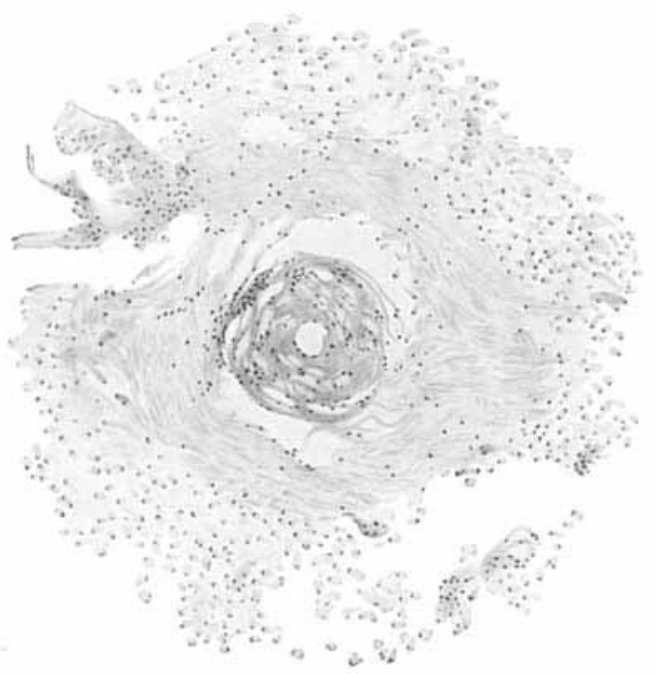

Frg. 11.

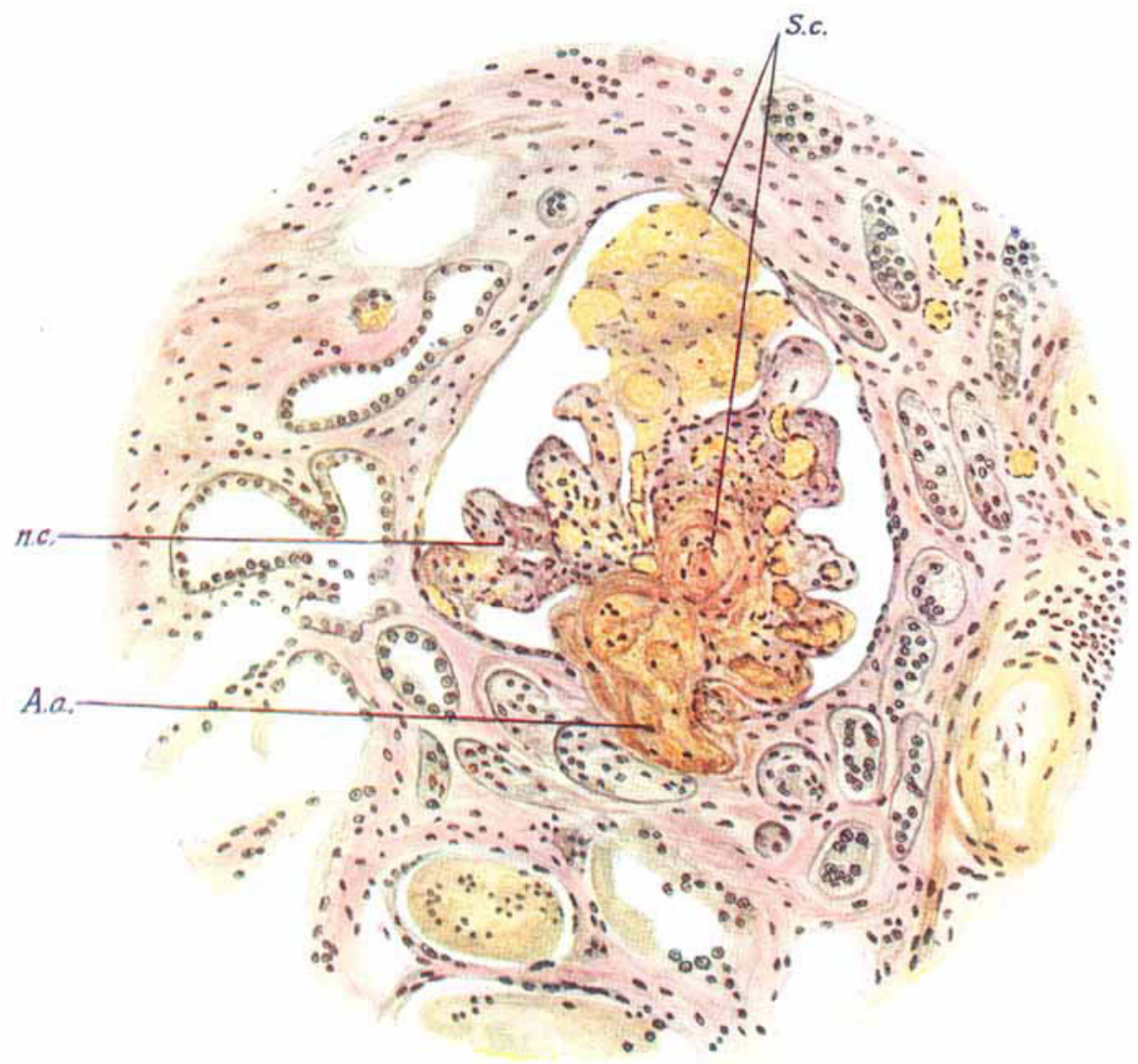

FIa, 12. 